\title{
DERIVACIONES DE LA ARQUITECTURA MUDÉJAR EN EL ESTADO DE MICHOACÁN, MÉXICO
}

\author{
Inés Ortiz Bobadilla
}

\section{INTRODUCCIÓN}

La conquista del Nuevo Mundo marcó el inicio de la evangelización de los indios de la Nueva España. Con ella se inició la llegada de las principales órdenes mendicantes, siendo los franciscanos los primeros en llegar en el año 1524; posteriormente, en 1526, arribaron los frailes dominicos y por último los agustinos en 1533. Cada una de las órdenes mendicantes, franciscanos, dominicos y agustinos, desarrollaron programas arquitectónicos de acuerdo a su intuición, necesidades y recursos de la localidad, tanto humanos como materiales. Se generó un acelerado proceso constructivo. Llegaron de España carpinteros, arquitectos, canteros, etc., para dar inicio a la vasta construcción de iglesias y conventos; sin embargo, estos esfuerzos no fueron suficientes. Kubler menciona la falta de personal cualificado para la construcción de los edificios: "A mediados del siglo XVI, las altas autoridades de la Iglesia y el estado se quejaban de la falta de personal capacitado" ${ }^{11}$. Debido a esto se construyeron escuelas de artes y oficios para instruir a los indios, inclusive se enviaban a éstos a la capital, para que aprendiesen las nuevas técnicas constructivas.

Se aplicaron las Ordenanzas de México para los gremios de carpinteros, entalladores, ensambladores y violeros (1568) y las Ordenanzas de Puebla para los gremios de carpintería y albañilería (1570), donde se efectuaban diferentes tipos de exámenes según el grupo del que se tratase; pero a diferencia de España, no se exigía a los postulantes haber cumplido un tiempo determinado de aprendizaje. Lo anterior se debe probablemente a la elevada producción constructiva de principios del virreinato, lo que ocasionó una preparación menos especializada de los alarifes.

La mano de obra que edificó los grandes complejos conventuales fue la de los indígenas, destacándose éstos por ser buenos trabajadores, que apren-

1. George Kubler, Arquitectura mexicana del siglo XVI, México, Fondo de Cultura Económica, 1982, p. 114. 
dían rápidamente las nuevas técnicas constructivas, “...que en todo género de oficios y artes se hacen en esta tierra de Indias (a lo menos en esta Nueva España) los indios son los que las ejercitan y labran, porque los españoles, maestros de los talleres de oficios, como hemos dicho, por maravilla hacen más que dar la obra a los indios y decirles cómo quieren que las hagan y ellos la hacen tan perfecta, que no se pueden mejorar" ${ }^{\prime 2}$. Incluso, como menciona Fray Jerónimo de Mendieta, a finales del siglo XVII existía al parecer un cierto orgullo por la construcción de sus nuevos templos, probablemente para competir con poblados aledaños, "Tratando de lo común, ¿quién ha edificado tantas iglesias y monasterios como los religiosos tienen en esta Nueva España, sino los indios con sus manos y propio sudor, y con tanta voluntad y alegría como edificaran casas para sí y sus hijos, y rogando a los frailes que se las dejasen hacer mayores?" ${ }^{3}$.

La aportación indígena en la realización de los edificios no fue solamente de mano de obra, sino también en aspectos técnicos, ya que eran ellos los que conocían los materiales de cada región, las condiciones climáticas, sísmicas, etc.

La arquitectura de la evangelización es fruto básicamente de tres corrientes principales, la arquitectura propia de la región, arquitectura prehispánica, la arquitectura importada por los españoles que sería la arquitectura del Renacimiento y la hispanomusulmana. Como menciona Juan B. Artigas "la elaboración del espacio arquitectónico interior de San Esteban Tizatlán se corresponde con la designación de espacio compartimentado con que Fernando Chueca Goitia se refirió a la arquitectura hispanomusulmana. A este efecto recordemos que dicho venero artístico, el islámico de España y del Mahgreb junto con el del Renacimiento italiano y el de la América precolombina, son los tres polos que originan el arte del dieciséis en México y que las tres corrientes aparecen constantemente en combinaciones diferentes aunadas a las necesidades de uso particulares del lugar de Nueva España en que se encuentran ubicados" ${ }^{4}$.

La arquitectura mudéjar derivada de la arquitectura hispanomusulmana pasa de igual modo a América, sin embargo no se puede hablar de mudéjares que hayan venido a estas tierras (aunque como se ve en el siguiente texto alguno sí pudo llegar al Nuevo Mundo) ya que estuvo prohibida la emigración de éstos a la Nueva España, según consta en un documento publicado por Toussaint "Sepades que Nos somos informados que a esas partes an pasado, y de cada día pasan, algunos esclavos y esclavas beberiscos e otras personas libres nuevamente convertidos de moros, e hijos dellos, estando por Nos prohibido que en ninguna manera pasen, por los muchos inconvenientes que por ex-

2. Fray Juan de Torquemada, Monarquía Indiana, México, Editorial Porrúa, 1975, p. 212.

3. Fray Gerónimo de Mendete, Historia Eclesiástica Indiana, p. 422, en Justino Fernández, Catálogo de construcciones religiosas del estado de Hidalgo, vol. 1, México, Talleres gráficos de la nación, 1940, p. XXVII.

4. Juan Benito Artigas, Capillas abiertas aisladas de México, México, Facultad de Arquitectura, UNAM, 1983, p. 138. 
periencia an parecido que de los que an pasado se han seguido, y porque se escusen los daños que podrían hazer los que ovieren pasado y de aquí adelante pasaren, porque en vna tierra nueva como esa, donde nuevamente plántase la fee, conviene que se quite toda ocasión para que no se pueda sembrar e publicar en ella la seta de Mahoma, ni otra alguna ofensa de Dios Nuestro Señor y perjuicio de nuestra sancta fee católica, visto y platicado en el nuestro Consejo de las Indias, fue acordado que debíamos mandar que todos los esclavos y esclavas berberiscos y personas nuevamente convertidas de moros o sus hijos, como dicho es, que en esas partes oviere, sean echados de la isla o provincia donde estuvieren e ynbiados a estos Reynos, de manera que en ninguna forma queden en esas partes..." ${ }^{5}$.

En México no se puede hablar de un edificio propiamente mudéjar a la manera de muchos de los españoles, pero sí de diferentes elementos mudéjares, tanto formales como estructurales, que se incorporaron a la arquitectura virreinal.

Una de las aportaciones mudéjares estructurales más importantes es el sistema de cubiertas de madera. Existe evidencia escrita en las fuentes históricas, de que había un conocimiento preciso para realizar este tipo de cubiertas en Nueva España. Desafortunadamente son pocas las que han sobrevivido.

Los primeros templos fueron construidos con cubiertas de madera por ser dicho material ligero, abundante, y de cierta facilidad constructiva. Asimismo por estar en una zona sísmica, las cubiertas de madera tenían una mejor respuesta a los temblores.

Estas cubiertas tenían como acabado final tanto teja como plomo, este último probablemente debido a su alto costo se utilizó por lo general sólo en los edificios más importantes, sobre todo en la ciudad de México. En algunos casos se empleaba una sobrecubierta o segunda cubierta que protegía de la intemperie a la armadura decorada.

Otro elemento que perdura hasta nuestros días, relacionado con las cubiertas de madera, son los canes. Estos se usaron principalmente como apoyos de las vigas en alfarjes de madera usando soluciones de uno, dos y hasta tres canes sobrepuestos, como en el caso de Erongarícuaro en Michoacán. Entre los canes generalmente hay aliceres o tableros, en algunas ocasiones decorados. En los casos de las fundaciones franciscanas existen, rematando los canes en la parte inferior y superior, molduras de madera en forma de cordón franciscano, que corren perimetralmente entre can y can.

Los pies derechos de madera son otro elemento importante de la arquitectura mudéjar que se encuentran en los edificios de la época virreinal, utilizados como apoyos verticales, generalmente rematados con zapatas que reciben las vigas a manera de capitel. Existen ejemplos que sostienen los entrepisos

5. Manuel Toussaint, Arte mudéjar en América, México, Instituto de Investigaciones Estéticas, UNAM, 1948, p. 120. 
de coros en iglesias, como elementos soportantes en claustros, inclusive como apoyos centrales en las cubiertas de madera en algunos templos de Michoacán, formando plantas de tipo basilical. También se suelen encontrar en los pórticos de casas y de plazas.

El alfiz es un elemento mudéjar que se repite constantemente en la arquitectura del siglo XVI. Lo encontramos en gran número de portadas de iglesias, enmarcando las puertas principales, ventanas simples o ajimezadas. El alfiz puede ser sencillo o doble, llegando inclusive a ser triple como en la iglesia de Angahuan, Michoacán, donde se realizaron tres recuadros a manera de alfices sobrepuestos uno encima del otro.

La decoración de lazo, tan característica de la arquitectura mudéjar, la encontramos principalmente en las cubiertas de madera, como en Tlaxcala, Huejotzingo en Puebla y de una menor calidad en la capilla de la tercera orden en Tulancingo, Hidalgo (actualmente desaparecida). Este tipo de decoración se realizó también en pintura, como en el caso de Atlatlahucan, Morelos, por ser esta solución más sencilla y económica que las complicadas armaduras de lazo.

\section{MiCHOACÁN}

Michoacán (fig. 1) es una región rica en bosques, por lo que existe una importante cultura maderera desde la época prehispánica. Sahagún relata acerca de los buenos carpinteros que había en este lugar: "sus casas eran lindas aunque todas eran de paja; los hombres lindos y primos oficiales, carpinteros, entalladores, pintores y lapidarios..." ${ }^{\prime}$. Alonso de la Rea también los alaba, "Justamente, son tan eminentes pintores con tan linda gala y primor, que todas las iglesias de esta provincia están adornadas de lienzos y láminas hechas de los mismos indios, sin que tengan que envidiar al pincel de Roma" ${ }^{7}$.

Existe evidencia de algunos lugares donde había techumbres de madera, ya sean alfarjes o armaduras, como por ejemplo en el convento de Tiripetío. Construido hacia 1549, tuvo una cubierta de armadura, probablemente de par y nudillo, "La iglesia fue toda de cal y canto, con una portada tan ilustre de columnas, que hasta hoy no se ha hecho otra como ella; una torre con muy lindas campanas y relox castellano. Todo era de muy buena obra, pero lo que más se aventajaba era la cubierta, que era de media tixera, toda llena de artesones, tan primos y obra tan delicada, que nadie la vía que no se admirara, y su gran-

6. Fray Bernardino de SAHAGún, Historia general de las cosas de la Nueva España, México, Editorial Porrúa, 1969, p. 207.

7. Alonso DE LA REA, Chronica de la orden de N. Seraphico P.S. Francisco, Provincia de S. Pedro y S. Pablo de Mechoacán, en Federico Gómez De Orozco, Crónicas de Michoacán, México, UNAM, 1972, p. 51. 


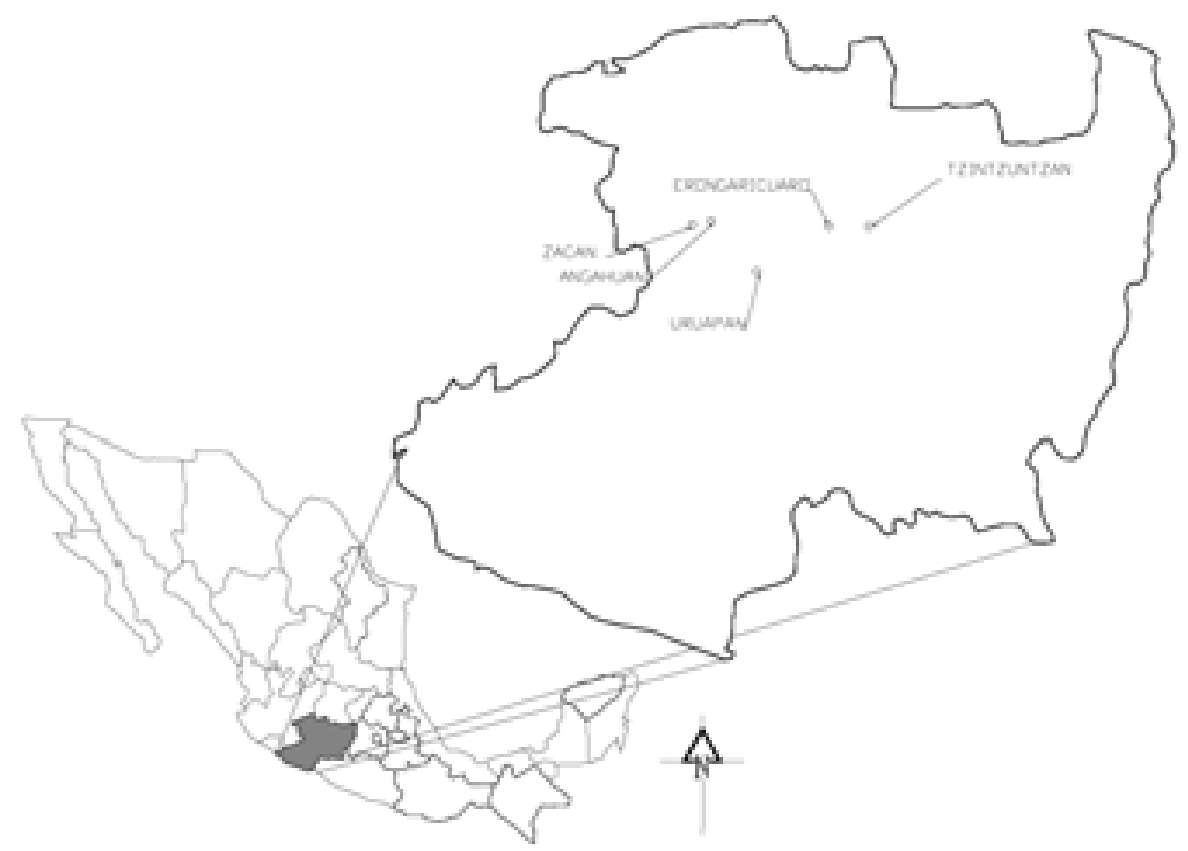

Figura 1. Mapa de la República Mexicana indicando el estado de Michoacán. Inés Ortiz Bobadilla.

deza se colegirá de que no se imitó en otro pueblo, por su costa" ${ }^{\prime 8}$. Este convento se destruyó por un incendio en 1640. Fray Matías de Escobar también habla de ella: “...jamás pudo imitarse la techumbre, o cielo de la iglesia, así como en la gran fábrica del mundo, lo más lucido y primoroso es el cielo, o bóveda celestial. Era todo de media tijera sobre la cual descansaban primorosos artesones, pedazos de aquel cielo, de que pendían multitud de doradas piñas, que como estrellas fijas se ascendían en aquel firmamento" ${ }^{\prime \prime}$.

El convento de Tacámbaro, construido en 1553, poseía un artesonado que también fue destruido por un incendio.

Respecto a la iglesia de Pátzcuaro, menciona Baselenque que se quiso hacer una iglesia de cinco naves que concurrirían todas al altar central. Las

8. Fray Diego de BAselendue, Historia de la Provincia de San Nicolás Tolentino de Mechoacán del Orden de S. Agustín, en F. GÓmez DE OrOzCO, op. cit., p. 62.

9. Fray Matías de Escobar, Americana Thebaida, Vitas patrum. De los religiosos hermitaños de N.P. San Agustín de la Provincia de San Nicolás Tolentino de Mechoacán, escrita por Fr. Matías de Escobar su cronista, año 1729, Michoacán, México, Ed. Balsal, 1970, p. 114. 
cubiertas serían de bóvedas, pero debido a lo pesado de la obra, terminaron haciendo una sola nave cubierta con una armadura de madera. "Puesta ya en Pátzcuaro la silla y catedral, trató de hacer iglesia, como de prestado, que esta que hoy tiene la compañía de Jesús muy suficiente para principiar; pero luego trató de hacer la iglesia catedral, que había de permanecer, la cual comenzó de cal y canto, de cinco naves, que todas iban a parar al altar mayor, y eran naves cerradas de bóveda, que los que estaban en la una no podían ver a los de la otra. Ella era una obra no vista en esta tierra, y con tanta grandeza se iba haciendo, que acabada pudiera ser la octava maravilla del mundo en edificios. El suelo no era tan fuerte como pedía obra tan pesada, y así comenzaron las paredes a abrirse... Quedó la nave de en medio que se levantó para cubrirla de madera y no de bóveda, y hoy está de media tijera muy hermosa, y tan capaz..."10. Actualmente tiene bóveda de madera que imita un cañón corrido.

Baselenque menciona, respecto a la iglesia de Ucareo, que tenía un alfarje de un solo orden de vigas "no hay cosa de bóveda, porque la tierra es fofa, si bien al cabo de tantos años se está el convento hoy en fortaleza y limpieza... La iglesia se fue haciendo después de madera porque el suelo no sufriera bóveda, más como señores del monte tiene unas madres por vigas tan bien labradas; que en esta materia no tiene semejante, no es de tijera sino enmaderado llano y encima bien enladrillado" ${ }^{\prime 1}$. También habla de la iglesia de Jacona que estaba cubierta con una techumbre de madera "hasta que el año de 1626 se cubrió de madera" ${ }^{12}$.

La iglesia de San Francisco en Uruapan probablemente tuvo un alfarje de un solo orden de vigas por lo que nos dice Ciudad Real, "El convento de Uruapan es de mediana capacidad; estaba todo acabado, con su claustro, dormitorios e iglesia; todo es de cal y canto, con su enmaderamiento y terrados... su vocación es de nuestro padre San Francisco"13.

En la iglesia de Nurio, que actualmente está cubierta con bóveda de madera, permanecen canes y zapatas que sobresalen de los muros, lo que indica que posiblemente tuvo un alfarje de madera.

Un elemento importante en la arquitectura religiosa de Michoacán fueron los hospitales o guatáperas que se construyeron para cuidar de los indios enfermos.

Manuel Toussaint, mencionando a Vasco de Quiroga explica que “Entonces concebió la idea de fundar instituciones hospitalarias en las que, al amor de los

10. Diego de BASELENQue, op. cit., capítulo XX, en Heriberto Moreno, introducción y notas, Los agustinos, aquellos misioneros hacendados. Historia de la provincia de San Nicolás Tolentino de Michoacán, escrita por Fray Diego de Baselenque, México, SEP, 1985, p. 178.

11. Ibídem, capítulo XVI, p. 143.

12. Ibídem, capítulo XVII, p. 147.

13. Antonio de Ciudad Real, Tratado curioso y docto de las grandezas de la Nueva España, México, UNAM, Instituto de Investigaciones Estéticas, 1976, vol. II, p. 166. 
pobres enfermos, todos los indios eran socorridos así en sus ansiedades materiales como en la vida del alma. El primer hospital que fundó fue el de Santa Fe, cerca de México, entre los años de 1531 y 1532. Todavía existe un recuerdo de lo que fue aquel hospital: "la organización del hospital, como había sido concebida por Don Vasco, abarcaba no solamente la curación de los enfermos, sino la vida de todos los que se relacionaban con ellos. Las Ordenanzas que dejó para los hospitales parecen inspiradas, como lo han descubierto los eruditos, en la célebre Utopía de Santo Tomás Moro, es decir, que aquello que pareció aún utópico para la Europa del Renacimiento, fue viable para el Nuevo Mundo"14.

Juan de Grijalva habla de estos hospitales, “En el reino de Michoacán se fundaron todos los conventos de nuestra Orden con un santo estatuto: que arrimado a las iglesias y a los conventos están edificados hospitales, donde traen todos los indios que enferman de cualquier condición que sean, y allí son curados y regalados mucho mejor en sus casas... Lo que ayudó mucho a estas fundaciones, y el principal motor y patrón de santa obra, fue aquel santo prelado y singular varón llamado Vasco de Quiroga, primer obispo de Michoacán..." ${ }^{\prime 15}$.

En Santa Fe de la ciudad de México, ya había construido Vasco de Quiroga un hospital, que también tenía escuela y algo parecido a un internado para niños. "Edificó un hospital de la cuna en este mismo pueblo de Santa Fe donde los indios que quisiesen así de la ciudad de México, como de otra cualquiera parte, pudiesen llevar a sus hijos, para que allí se los criasen... junto a este hospital, hizo un colegio donde los muchachos y adultos aprendían a leer, y escribir, canto llano, y canto de órgano, y todo género de instrumentos músicos... pegado a este hizo un hospital donde se curasen los enfermos..."16.

Aunque existía la idea de comenzar estos hospitales, únicamente fue en Michoacán donde realmente funcionaron, "que en los hospitales de Nueva España no se ha podido ni puede acabar con ellos que acudan al hospital a curarse cuando están enfermos, y así no han servido ni sirven los dichos hospitales sino para dos ó tres mancos ó paralíticos, cuando mucho, y á veces sólo uno, que sirve allí de cabeza de lobo para que los principales hagan sus mangas; excepto en la provincia de Mechoacán solamente, adonde parece que ha cuadrado más este negocio y tenido mejor suceso..."17.

Torquemada escribe también del fracaso de los hospitales en la mayoría de los lugares, excepto en Michoacán y Jalisco, “En la provincia de Mechoacán, y Jalisco, lo reciben todos, por tener tal concierto, que todos ellos, desde el

14. Manuel Toussaint, Pátzcuaro, México, Imprenta universitaria, 1942, p. 25.

15. Juan de Grijalva, Crónica de la orden NPS Agustín, México, Ed. Porrúa, 1985, p. 154.

16. Ibídem, p. 45.

17. Joaquín García ICAZBALCETA, Códice Franciscano del siglo XVI. Informe de la Provincia del Santo Evangelio al visitador Lic. Juan de Ovando. Informe de la Provincia de Guadalajara al mismo. Cartas de religiosos, 1533-1569, México, Imprenta de Francisco Díaz de León, 1889, p. 74. 
Mayor, hasta el Menor, van a curarse, y morir en el Hospital...; fuera de aquellas provincias, en todas las demás, no se pudo, ni puede acabar con los Indios, que entren en el Hospital a curarse...; y hospitales hechos, y muchos por no ser de provecho, se han dexado, y se han arruinado y caído"18.

Dentro del partido arquitectónico de estos edificios está siempre presente una capilla. Ésta generalmente ha sido cubierta con techumbres de madera, ya sea con alfarjes de un solo orden de vigas o con techumbres derivadas de la arquitectura mudéjar. Las naves son generalmente rectangulares con presbiterio del mismo ancho que la nave, aunque hay casos de naves rectangulares separadas con pies derechos de madera, formadas a modo de planta basilical, donde las naves laterales están cubiertas con alfarjes de un solo orden de vigas y la central, cubierta con una estructura que imita la armadura de par y nudillo, creando una superficie trapezoidal (véase figura 2). También hay casos donde se cubre con bóvedas de madera.

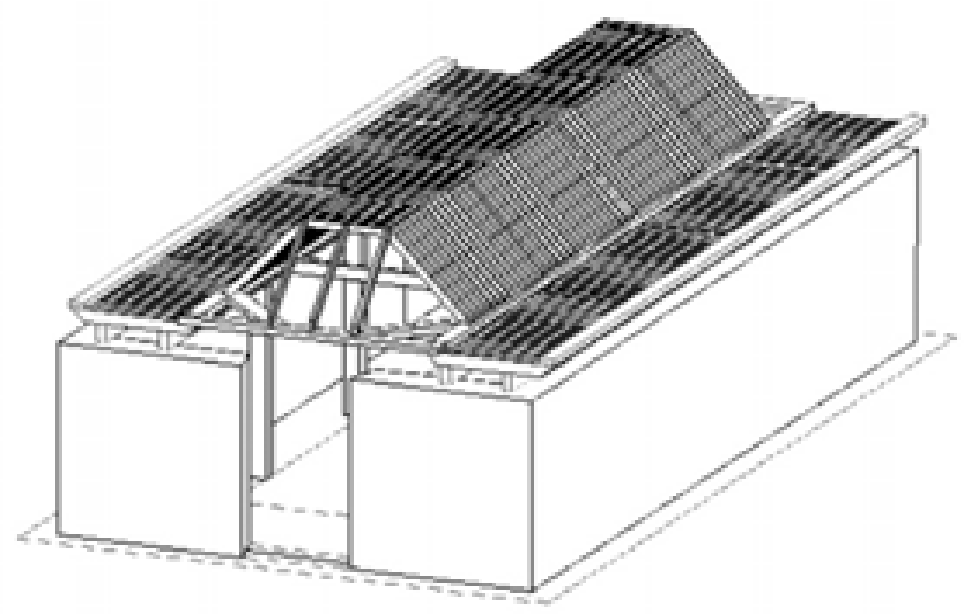

Figura 2. Cubierta trapezoidal y alfarje en naves laterales. Inés Ortiz Bobadilla.

En los casos estudiados en Michoacán, encontramos cubiertas de un solo orden de vigas apoyadas, ya sea directamente sobre el muro o estribos, o bien sobre canes sencillos, dobles y triples (véase figura 3).

En el caso de alfarjes apoyados sobre canes sencillos tenemos la capilla del Santo Sepulcro, en Uruapan, la capilla del hospital en Angahuan y la iglesia de San Pedro en Zacán.

18. Fray Juan de TORQuEMADA, op. cit., p. 199. 
En el caso de alfarjes sobre dobles canes no se incluye ningún caso en este artículo, pero bien podemos mencionar como ejemplos la iglesia de Huiramangaro, San Andrés Tzirondaro, Naranja (solo en la nave).

Erongarícuaro es el único caso de alfarje con canes triples.

Alfarjes apoyados directamente sobre el muro o estribos se encuentran en la capilla abierta del hospital de Tzintzuntzan (sin incluir la zona del presbiterio).

En el convento de Tzintzuntzan encontramos la decoración de lacería en las esquinas del claustro de clara influencia mudéjar.

Por otra parte están las derivaciones de la arquitectura mudéjar, por un lado las iglesias con planta basilical separadas con pies derechos de madera, con cubiertas trapezoidales en la nave central y alfarjes en las laterales (véase figura 4). Ejemplos con esta solución están, la capilla de San Francisco, la capilla de San Miguel Arcángel, la capilla del Señor Santiago Apóstol (aunque en la nave central posee una cubierta de madera con bóveda de cañón) y la capilla del hospital de Zacán.

También existen ejemplos de iglesias con cubiertas trapezoidales que imitan armaduras de par y nudillo (véase figura 5). Otro tipo sería el caso del presbiterio de la iglesia de Angahuan, que asemeja una gran artesa apoyada perimetralmente sobre canes. También el presbiterio de la capilla abierta del hospital de Tzintzuntzan, aunque con una solución diferente, tiene una cubierta con una sencilla artesa invertida.

Cubiertas con bóvedas de madera (véase figura 6) pueden verse asimismo en Michoacán, como es el caso de la que cubre la iglesia de la tercera orden en Tzintzuntzan o la nave de la iglesia de Angahuan.

La región de Michoacán, como se había mencionado anteriormente, es rica en cubiertas construidas con madera y existen un sinnúmero de ejemplos, sobre todo en edificios religiosos, edificados con este material.

Existen publicaciones importantes al respecto como las escritas por Juan Benito Artigas ${ }^{19}$, donde analiza las principales guatáperas de la región purépecha. Luis Alberto Torres Garibay ${ }^{20}$ menciona las cubiertas ubicadas en la región lacustre de Pátzcuaro y hace una importante aportación analizando el sistema estructural de éstas. Gloria Álvarez Rodríguez ${ }^{21}$ analiza los artesones historiados de la región de Michoacán, en su tesis doctoral presenta las cu-

19. Juan Benito ARTiGAs, Pueblos, Hospitales y Guatáperas de Michoacán, las realizaciones arquitectónicas de Vasco de Quiroga y Fray Juan de San Miguel, México, UNAM, Gobierno del estado de Michoacán, 2001.

20. Luis Alberto Torres GARIBAY, Tecnología constructiva en la zona lacustre de Pátzcuaro y región Morelia, Tesis para obtener el grado de Doctor en Arquitectura, México, UNAM, 1999.

21. Gloria A. ÁlvArez, Los artesones michoacanos, Tesis presentada para obtener el grado de Doctor en Arquitectura, México, UNAM, 1998. 


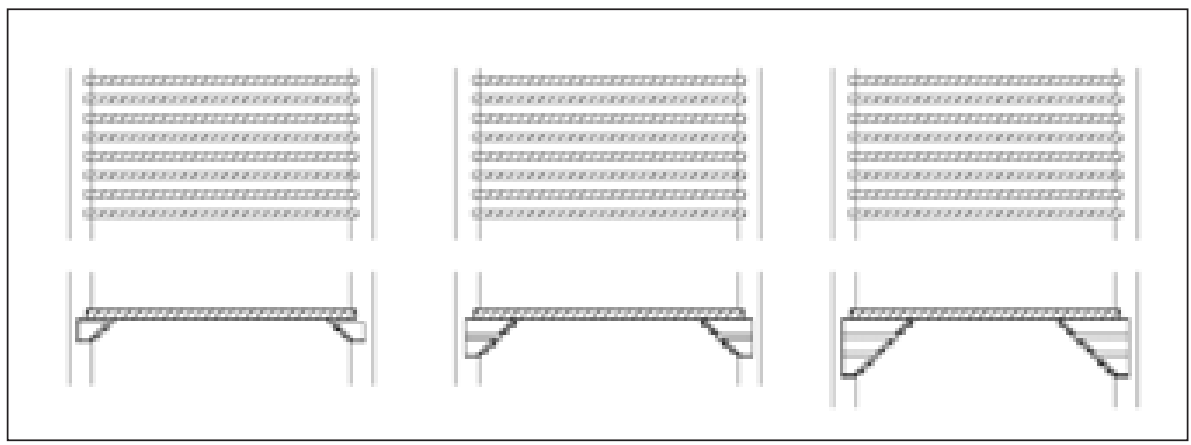

Figura 3. Alfarje de un solo orden de vigas apoyado sobre uno, dos y tres canes. Inés Ortiz Bobadilla.

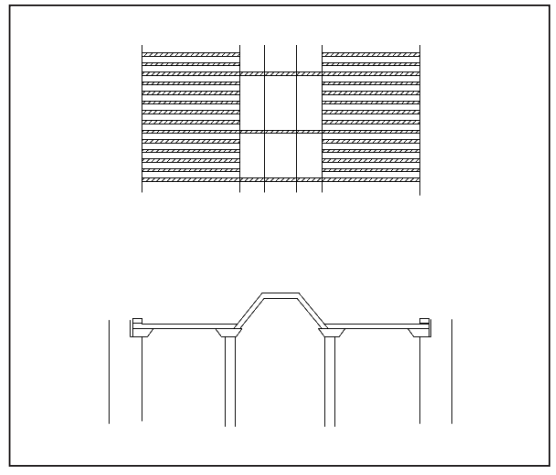

Figura 4. Cubierta trapezoidal y alfarje en naves laterales. Inés Ortiz Bobadilla.

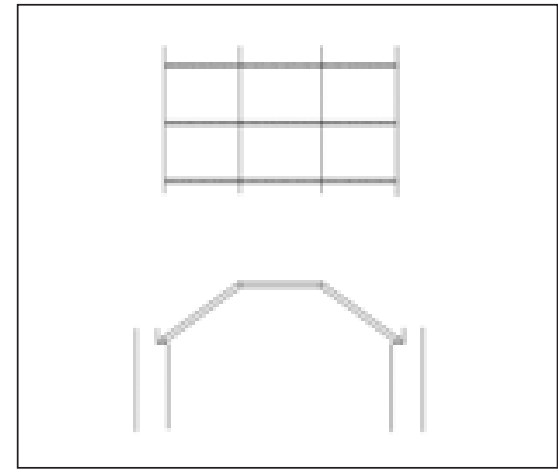

Figura 5. Cubierta trapezoidal. Inés Ortiz Bobadilla.

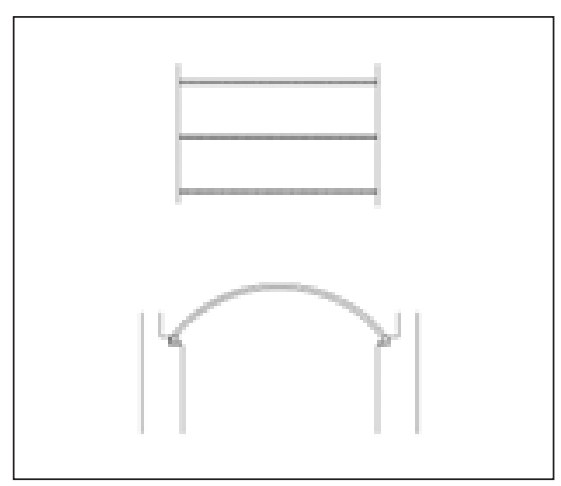

Figura 6. Cubierta abovedada. Inés Ortiz Bobadilla. 
biertas de la región, donde se puede encontrar una lista muy completa de los diferentes inmuebles que poseen cubiertas de madera, diferenciadas según su sistema estructural.

En este artículo se han incluido los inmuebles mencionados por los cronistas y que en su conjunto dan una muestra panorámica de los diferentes tipos de cubiertas que se realizaron en Michoacán.

\section{TEMPlo DE SAn Francisco, TzinTZUnTZAN}

Tzintzuntzan significa "lugar del colibri" 22. Los franciscanos se establecieron hacia 1525 en Tzintzuntzan, desde donde Fray Martín de Valencia inició la evangelización de Michoacán. Vasco de Quiroga estableció en este lugar, en 1538, la primera sede del obispado de Michoacán. El convento franciscano se construyó después de 1533, bajo la dirección de Fray Juan de San Miguel, ${ }^{23}$ y fue sustituido por completo probablemente en 1596, bajo la supervisión de Fray Pedro de Pila. Ciudad Real menciona sobre este lugar que "El convento es bueno y está acabado, hecho de cal y canto, con su claustro, dormitorio e iglesia, la cual tiene un retablo muy vistoso; hay dentro en casa un aljibe de agua llovediza y una buena huerta... la vocación de aquel convento es de nuestro padre San Francisco" ${ }^{\prime 24}$.

Posteriormente, en la inspección ocular en Michoacán, mencionan que "la iglesia consta de una nave, torre adjunta, piezas separadas de sacristía y bautisterio, coro alto, órgano sin uso, entablados superior e inferior, techo de teja, nueve altares formales y otros tantos retablos, todo en buen estado y de decente aspecto... Hay también una capilla de la Soledad de excesiva longitud, con un solo retablo dorado, cielo superior de tablas, mal pintado y paredes de adobe... La capilla del hospital es la menos aseada y capaz, y las ruinas a ella vecinas, manifiestan hubo en otro tiempo formales enfermerías... El templo de la tercera orden, también de adobe con la torre adjunta, tiene entablados el pavimento y el cielo..." 25 .

Diego Angulo escribe acerca de la portada de la iglesia refiriéndose a las características del primer Renacimiento en México: "lo más original de ella es el segundo cuerpo rehundido y formado por un doble arco con alfiz, que sirve de base al frontón con enorme venera que corona la portada. En esa gran venera se diría que culmina el leit motiv de la portada y de la obra toda de su autor. En pequeño, alternando con florones, decora una de las arquivoltas, y se repite de mayor

22. Enciclopedia de los municipios de México, en la página de internet http:/ / www.e-local.gob.mx/ wb2/ELOCAL/ELOC_Enciclopedia

23. George KUBLER, op. cit., p. 599.

24. Antonio de CiUdAD ReAl, op. cit., vol. II, p. 77.

25. José Bravo Ugarte, Inspección Ocular en Michoacán, Regiones central y sudoeste, México, Testimonia Histórica n. ${ }^{\circ}$ 2, Ed. Jus S.A., 1960, p. 34. 


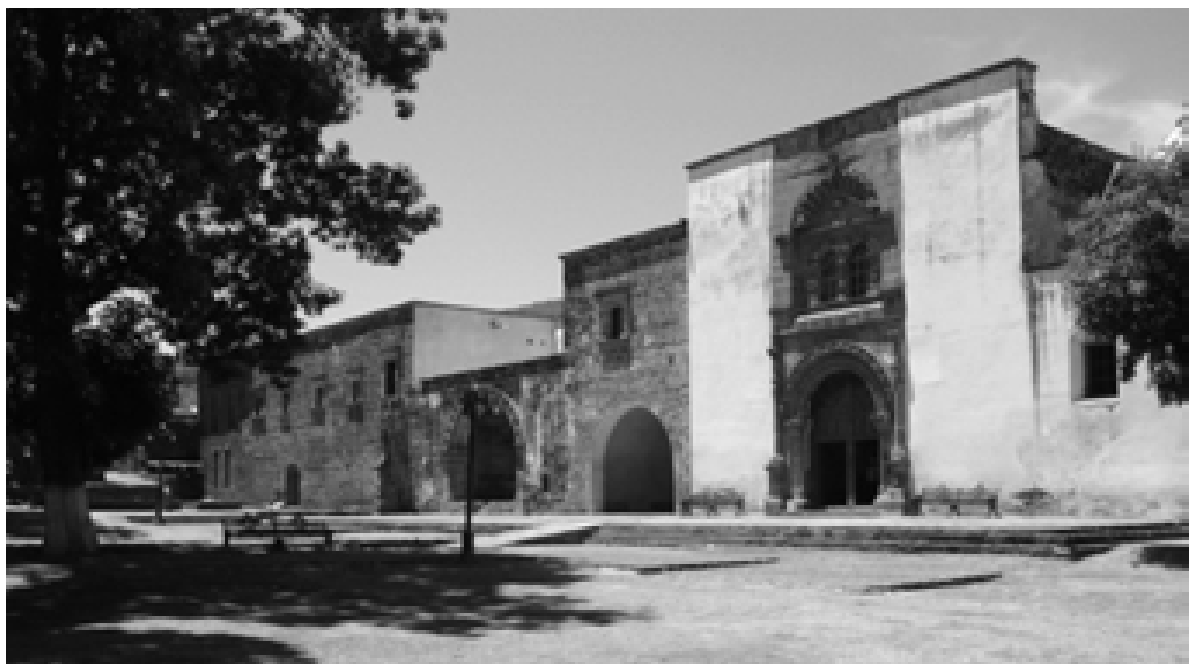

Figura 7. Fachada principal de San Francisco, Tzintzuntzan, Michoacán. Rodrigo Floresvillar Ortiz.

tamaño en el segundo cuerpo, donde no sólo se le esculpe en las jambas, sino que se subraya su importancia colocándola sobre varias hojas de tamaño grande ${ }^{\prime 26}$.

El convento, como la mayoría del siglo XVI, tiene entrepisos de alfarjes de un solo orden de vigas. Lo que nos ocupa en este sitio es la decoración de lazo en las esquinas del claustro de clara influencia mudéjar (véase figura 8).

Tiene una estrella de doce puntas con un florón al centro, pintado el lazo en tonos azules. El lazo es ataujerado, es decir, la lacería se sobrepone a la armadura, esto supone menor trabajo de precisión que cuando la lacería es apeinazada, más complicada porque van entremezcladas la estructura misma de la armadura con la decoración.

El templo de la Tercera orden (véase figura 10) como indica Ciudad Real tenía "entablados el pavimento y el cielo", actualmente posee una bóveda de madera (véase figura 11).

La capilla del hospital (véase figura 12), que según la Inspección Ocular de Michoacán "es la menos aseada y capaz, y las ruinas a ella vecinas, manifiestan hubo en otro tiempo formales enfermerías...", formada por tres arquerías de medio punto, tiene una cubierta de un alfarje de un solo orden de vigas y en la zona del presbiterio una cubierta de madera en forma de artesa invertida (véanse figuras 13 y 14). Conserva restos de pintura en sus muros.

26. Diego Angulo IÑIgueZ, Historia del arte Hispanoamericano, Barcelona, Salvat, 1950, p. 362. 


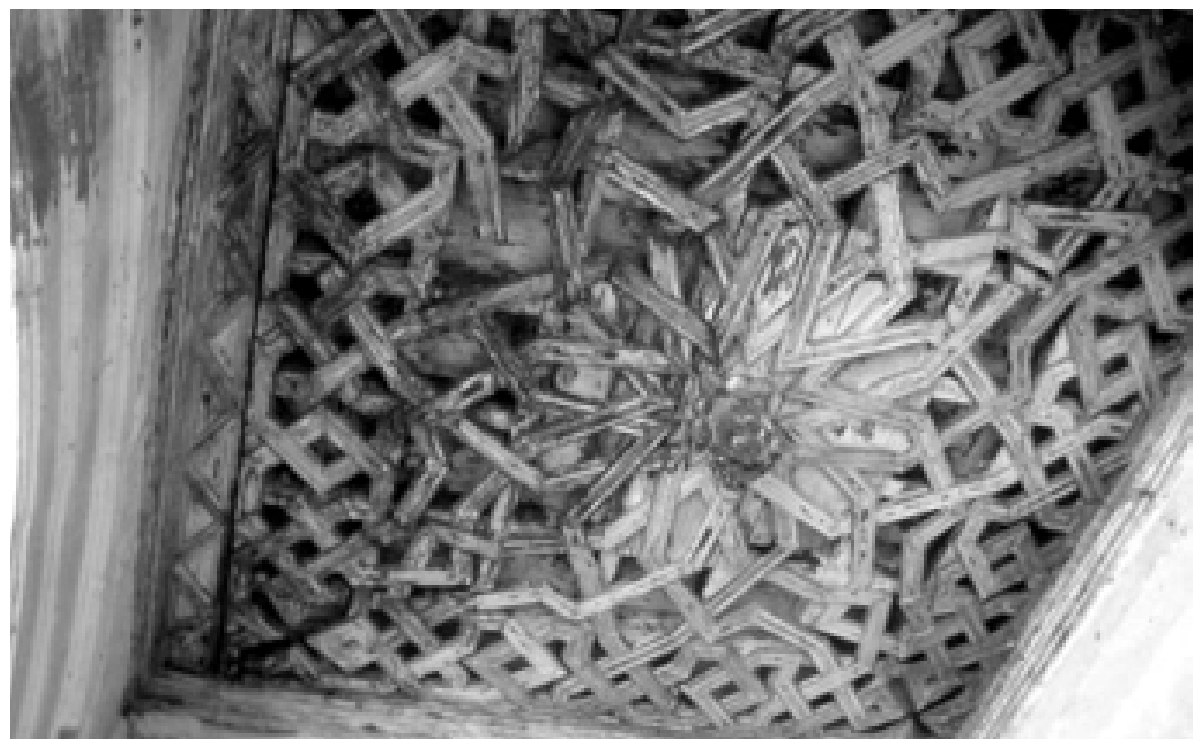

Figura 8. San Francisco, Tzintzuntzan. Decoración de lazo en las esquinas del convento. Inés Ortiz Bobadilla.

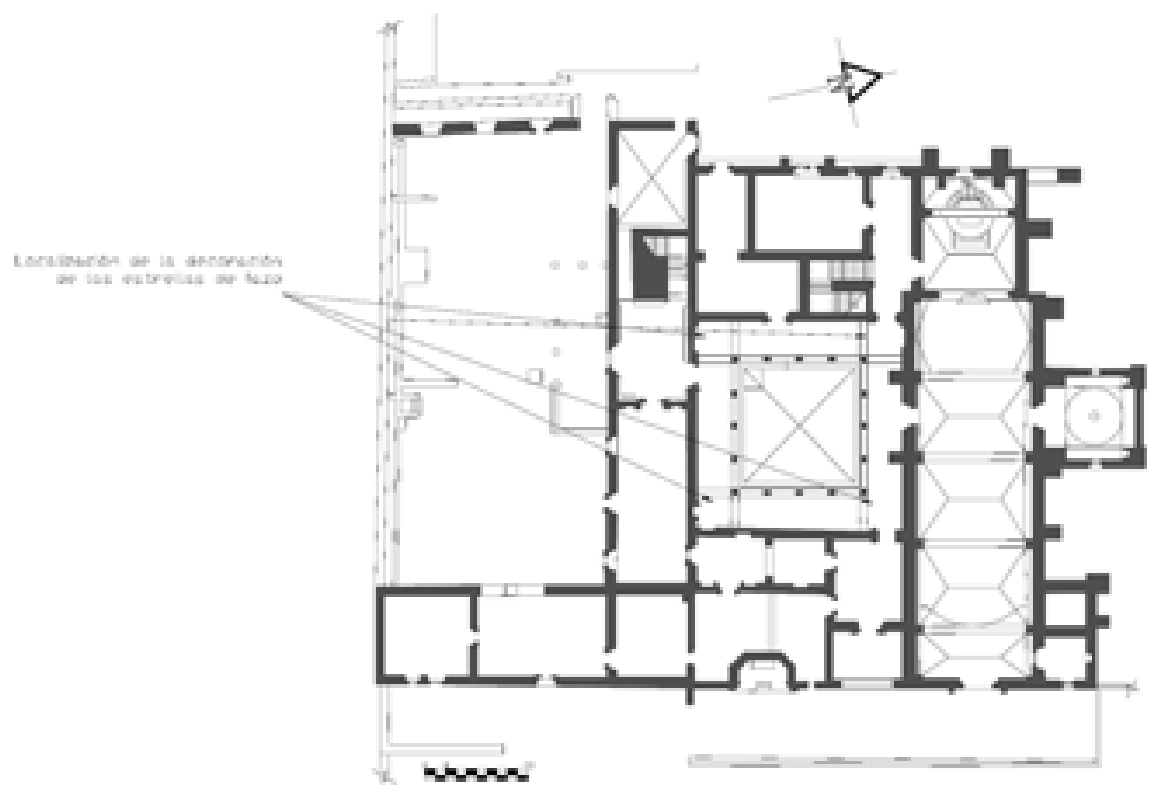

Figura 9. Plano del conjunto conventual de Tzintzuntzan. Basado en C.M.S.R.L.P. 


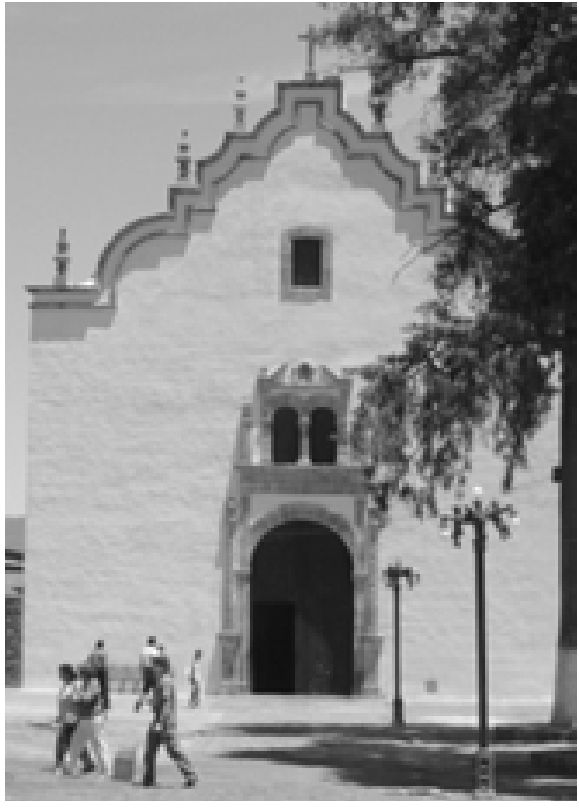

Figura 10. Fachada principal del templo de la tercera orden, Tzintzuntzan, Michoacán. Inés Ortiz Bobadilla.

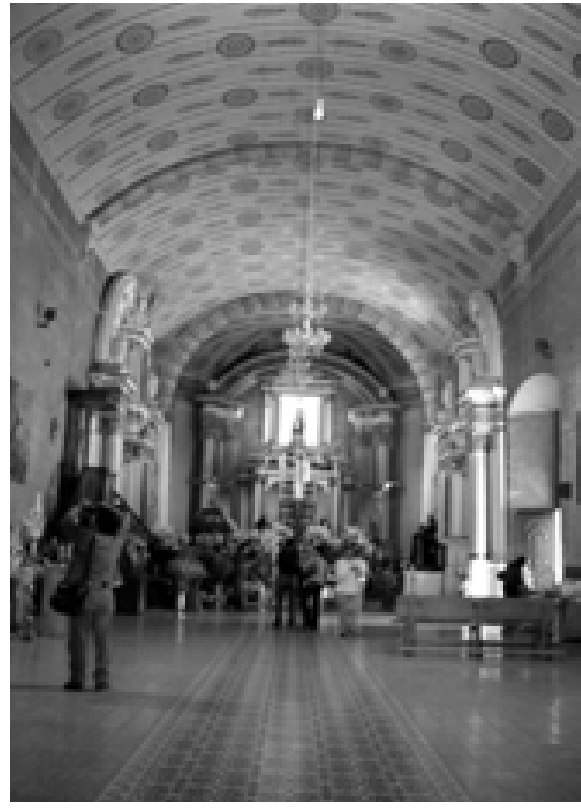

Figura 11. Interior del templo de la tercera orden, Tzintzuntzan, Michoacán. Inés Ortiz Bobadilla.

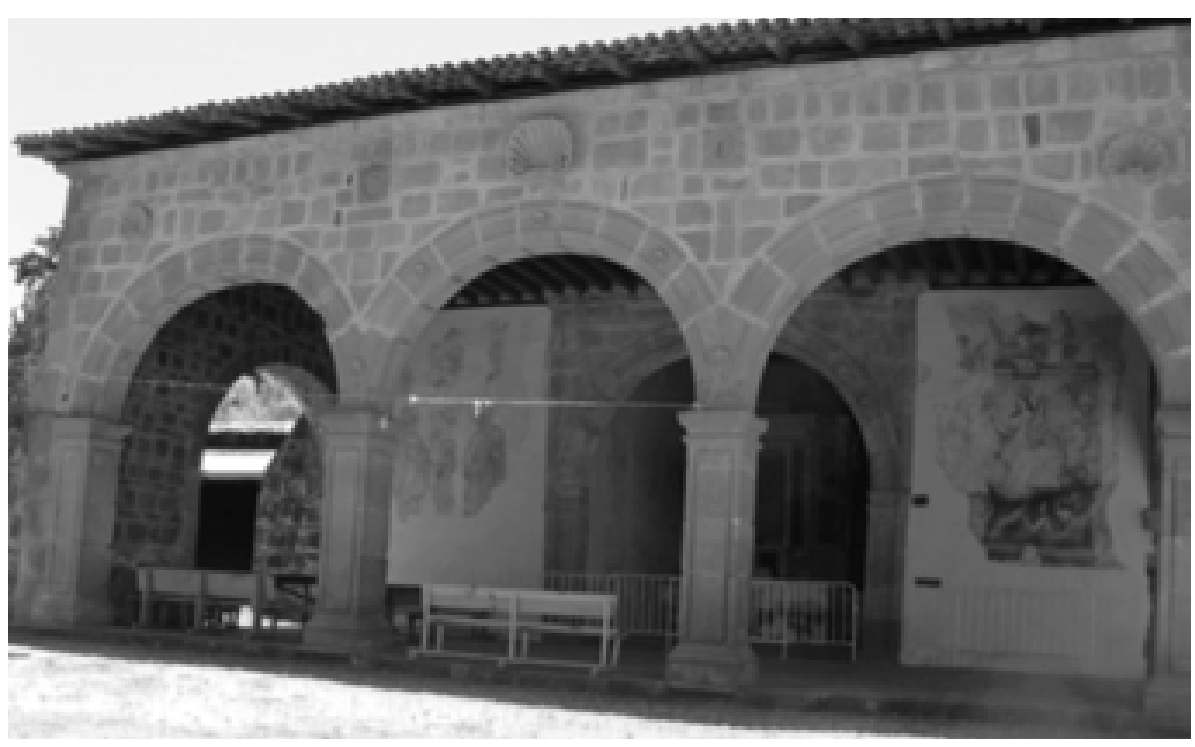

Figura 12. Vista de la fachada de la capilla abierta del hospital de Tzintzuntzan, Michoacán. Rodrigo Floresvillar Ortiz. 


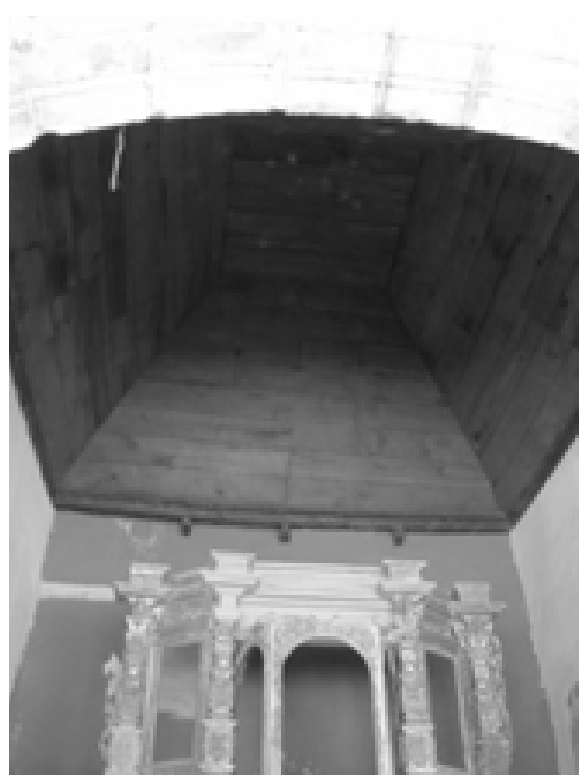

Figura 13. Vista de la cubierta de la capilla abierta del hospital de Tzintzuntzan, Michoacán. Rodrigo Floresvillar Ortiz.

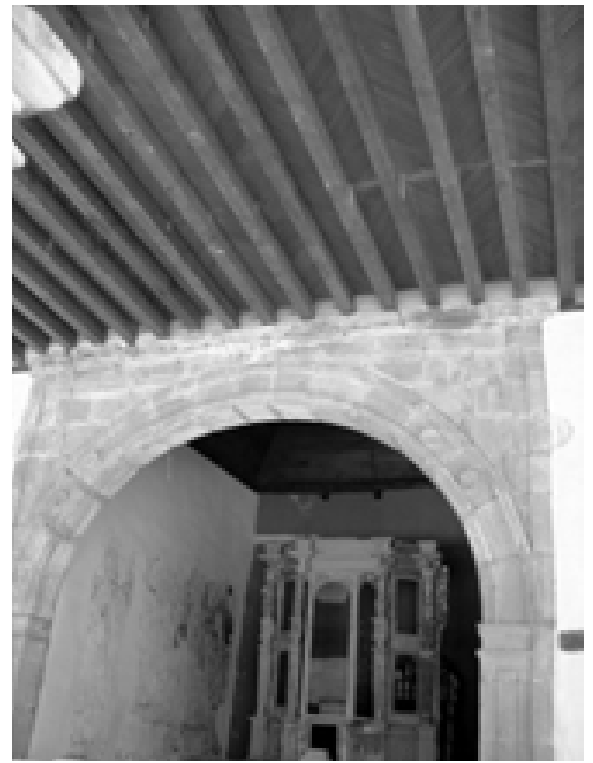

Figura 14. Vista de la cubierta de la capilla abierta del hospital de Tzintzuntzan, Michoacán. Rodrigo Floresvillar Ortiz.

\section{Iglesia de Nuestra SeÑora de la Asunción, ERONGARÍCUARO}

Erongarícuaro significa "lugar de Atalaya", otra acepción sería "lugar de espera o resurrección" ${ }^{\prime 27}$. El convento de Erongarícuaro fue fundado por los franciscanos entre 1563 y 157028, sin embargo, Diego Angulo ubica su construcción en $1575^{29}$.

Ciudad Real describe el lugar, "El convento estaba todo acabado con su iglesia; solamente le faltaba por cubrir los corredores altos del claustro; viene a la huerta una fontecita de buena agua, que se trae por unas canales de madera que llaman canoas, está edificado en un alto, orilla de la mesma laguna, y descúbrese desde él gran parte della; su vocación es de la Asumpción de nuestra Señora" ${ }^{\prime 30}$.

27. Enciclopedia de los municipios de México, en la página de internet http:/ / www.e-local.gob.mx / wb2/ELOCAL/ELOC_ Enciclopedia

28. George Kubler, op. cit., p. 594.

29. Diego Angulo IÑigueZ, op. cit., p. 253.

30. Antonio de CiUdad Real, op. cit., vol. II, p. 80. 
En la Inspección Ocular de Michoacán escriben acerca de la iglesia: “consta de una nave con entablados superior e inferior, paredes de piedra y lodo, torre de lo mismo embutida en la nave, debajo el bautisterio, coro alto con órgano descompuesto, pieza clara de sacristía, techo de teja y ocho altares formales" ${ }^{\prime 31}$.

La portada (véase figura 15) tiene un arco de medio punto enmarcado por un alfiz decorado con grandes veneras y sobre él una ventana en ajimez, también enmarcada con un alfiz; termina el edificio en un cuerpo triangular. Esta portada es comparada por Angulo con la de la iglesia de Tzintzuntzan "con enormes veneras, rígidas hojas y anchos capiteles con gruesos caulículos" ${ }^{32}$.

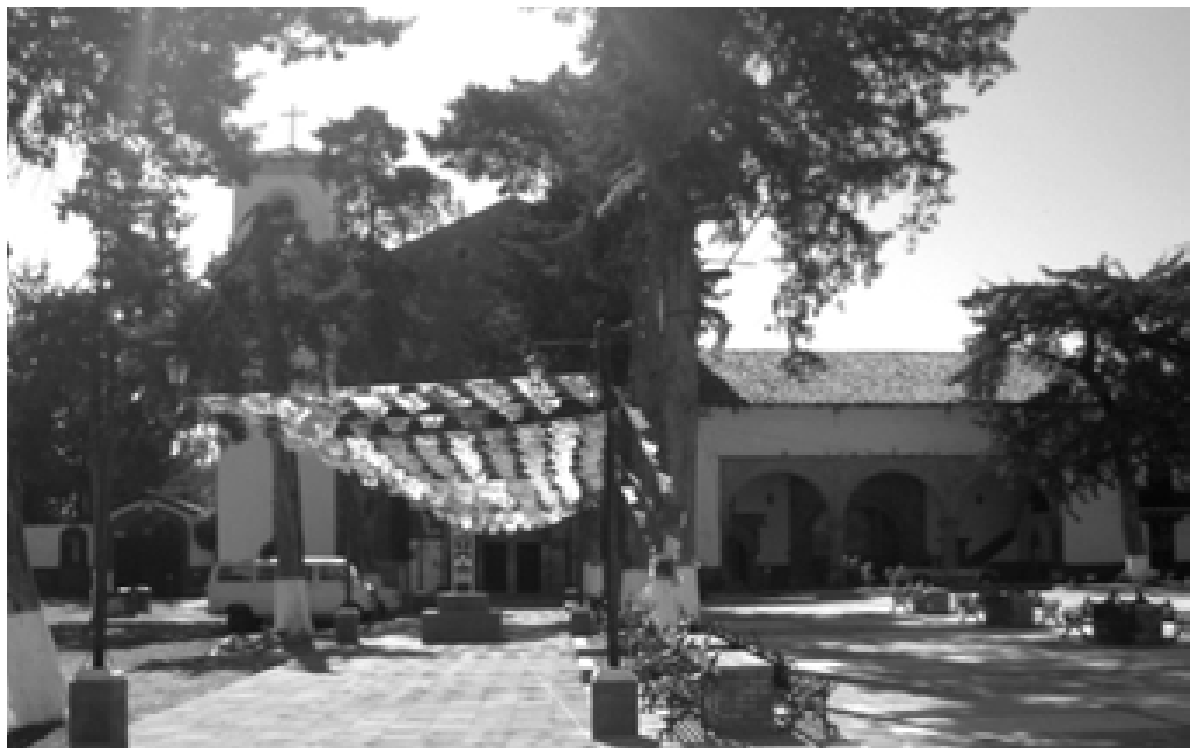

Figura 15. Fachada principal de Nuestra Señora de la Asunción, Erongarícuaro, Michoacán. Rodrigo Floresvillar Ortiz.

A la izquierda del templo se localiza una capilla abierta y a la derecha una torre campanario.

La planta es una nave rasa de aproximadamente $11,50 \mathrm{~m}$ de ancho por $50,50 \mathrm{~m}$ de longitud, el presbiterio es del mismo ancho que la nave, diferenciado por un arco triunfal y por un desnivel en el piso y en la cubierta (véase figura

31. José Bravo UGarte, op. cit., p. 59.

32. Diego Angulo IÑIguEZ, op. cit., p. 364. 


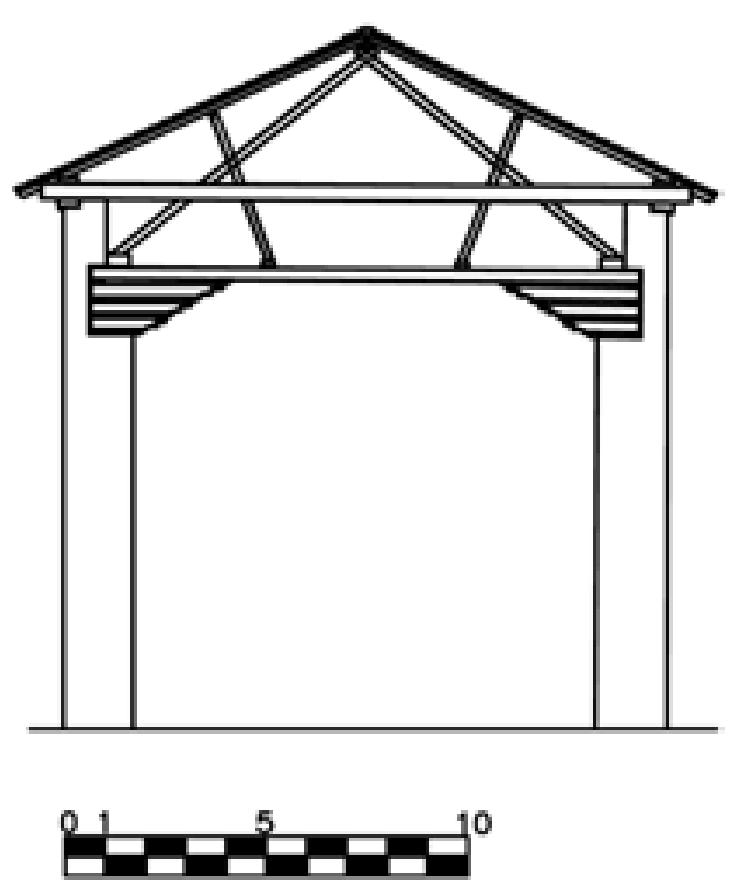

Figura 16. Corte transversal de Nuestra Señora de la Asunción, Erongarícuaro. Basado en Luis Alberto TORRES GARIBAY, Tecnología constructiva en la zona lacustre de Pátzcuaro y región Morelia.

18). El coro se encuentra al inicio de la nave con tribunas laterales en los dos lados y está apoyado sobre pies derechos y vigas. El entrepiso es de un alfarje de un solo orden de vigas apeado sobre canes sencillos (véase figura 19).

Al igual que el coro, la cubierta de la nave es de un alfarje de un solo orden de vigas, pero en este caso apoyado sobre triples zapatas que dan un apoyo de 2,20 $\mathrm{m}$ a cada lado a las vigas (véase figura 20). Cada nivel de canes está decorado con un cordón franciscano. Los muros de piedra y lodo tienen un espesor de 1,85 a 1,95 $\mathrm{m}^{33}$. Protegiendo a la techumbre interior tiene una $\mathrm{cu}^{-}$ bierta de una armadura de madera (véanse figuras 16 y 17).

33. Luis Alberto TORRES GARIBAY, op. cit., p. 232. 


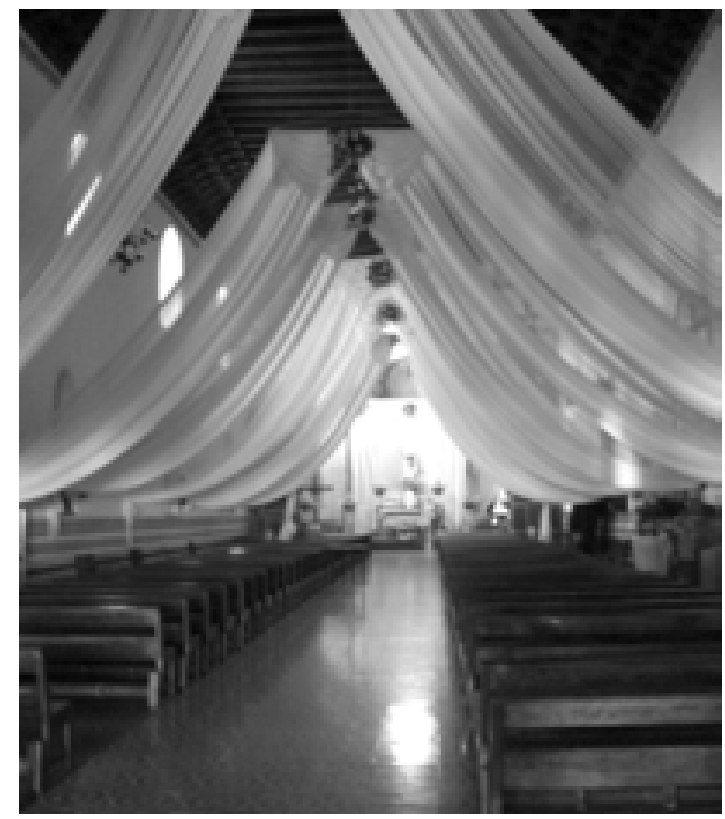

Figura 17. Vista del interior de Nuestra Señora de la Asunción, Erongarícuaro. Rodrigo Floresvillar Ortiz.

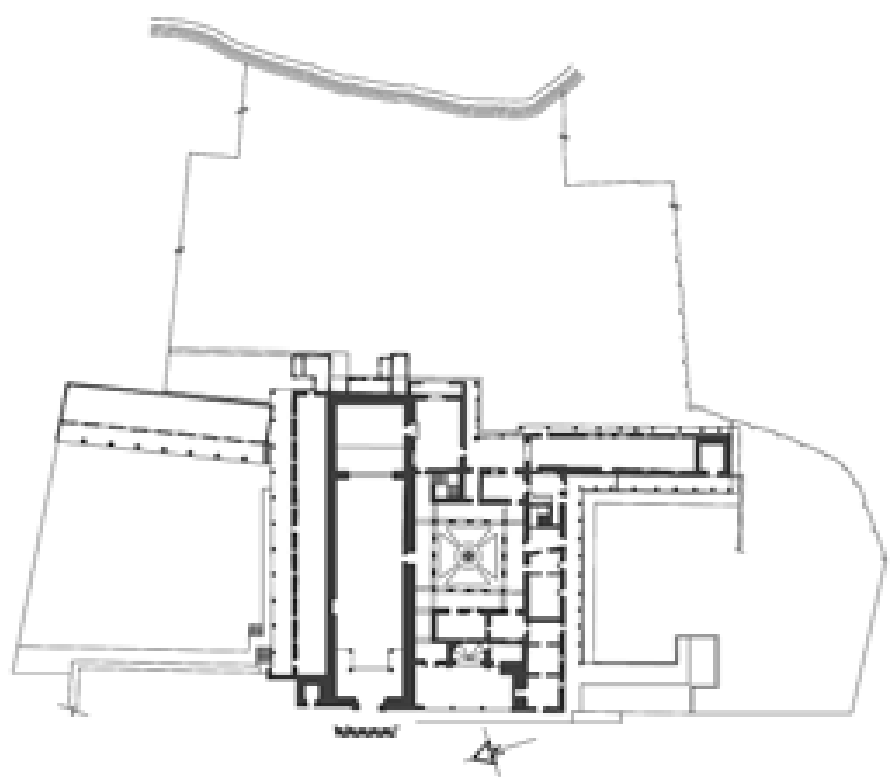

Figura 18. Planta de Nuestra Señora de la Asunción, Erongarícuaro. Basado en C.M.S.R.L.P. 


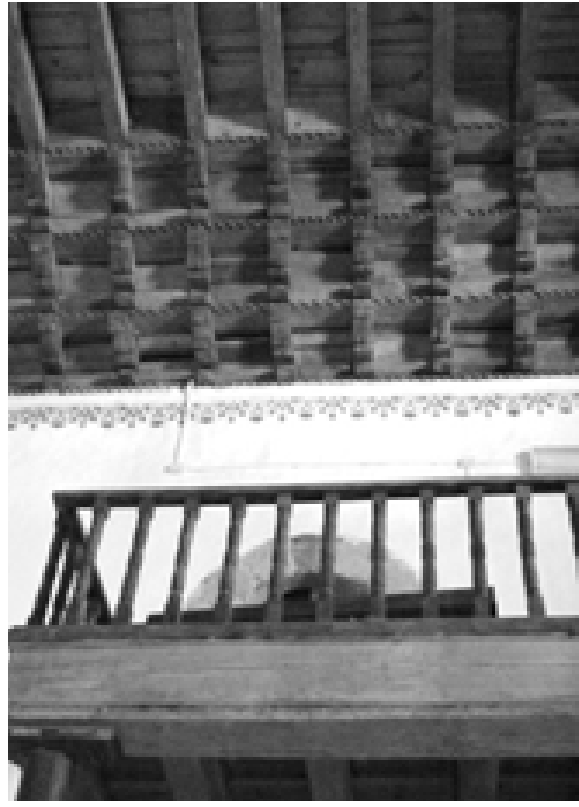

Figura 19. Detalle del coro de Nuestra Señora de la Asunción, Erongarícuaro. Rodrigo Floresvillar Ortiz.

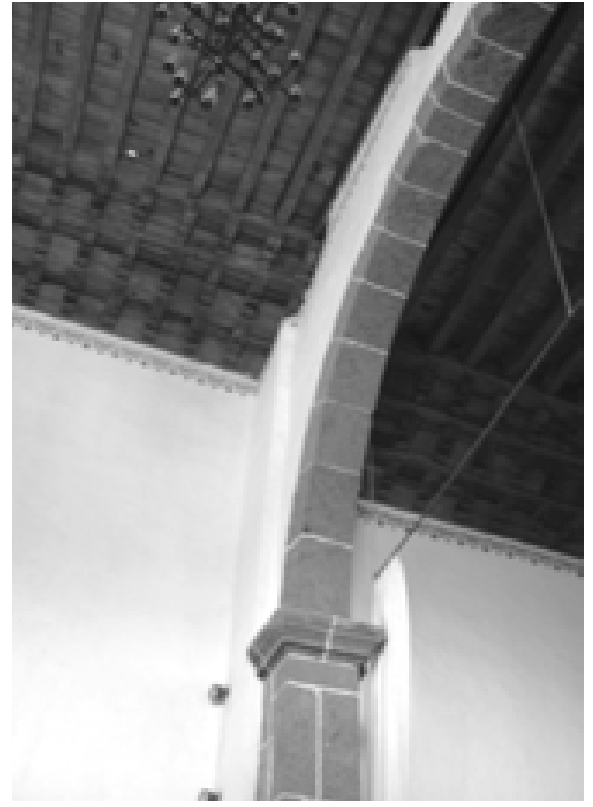

Figura 20. Detalle de los triples canes en la zona del presbiterio de Nuestra Señora de la Asunción, Erongarícuaro. Rodrigo Floresvillar Ortiz.

\section{URUAPAN}

Uruapan fue fundado por Fray Juan de San Miguel, quien construyó una iglesia, el hospital y dividió la ciudad en nueve barrios donde edificó nueve capillas, "En donde dejó más señaladas las huellas de su fervoroso espíritu, y en lo material más perpetuas memorias de su aplicación a lo político, fue en el pueblo de Uruapan... repartiendo la población en sus calles, plazas y barrios, con tan linda disposición que pudiera emular la aristocracia de Roma... trató el Siervo de Dios de fabricar una iglesia a todo costo, pues la que antes tenían aunque era muy capaz, era toda de tablas y madera... comenzaron a juntar materiales y a poner por otra iglesia muy grande, suntuosa, como para concurso tan crecido, siendo su labor de calicanto, y tan costosa, que pudiera consumir un patrimonio... Después de esto emprendió la obra de un Hospital para la curación de los indios enfermos... Fundado el pueblo, hecha la iglesia, y acabado el Hospital, repartió él la población en sus barrios, dándole a cada uno de ellos su capilla con el retablo del Santo... como cada capilla está en los remates de las calles, unas a otras se están mirando y hermoseando la disposición del 
Pueblo; y como está dividido en nueve barrios, son nueve las capillas..." 34 (véase figura 21). Las capillas que quedan ya no se pueden ver una a la otra por el crecimiento de la ciudad. A finales del siglo XVIII, según la Inspección Ocular de Michoacán, las capillas estaban en ruinas y ya no se utilizaban: "Compónese este pueblo de siete barrios y en cada uno de ellos existe una capilla en tan mal estado, que en ninguna se dice ya misa" ${ }^{\prime 35}$.

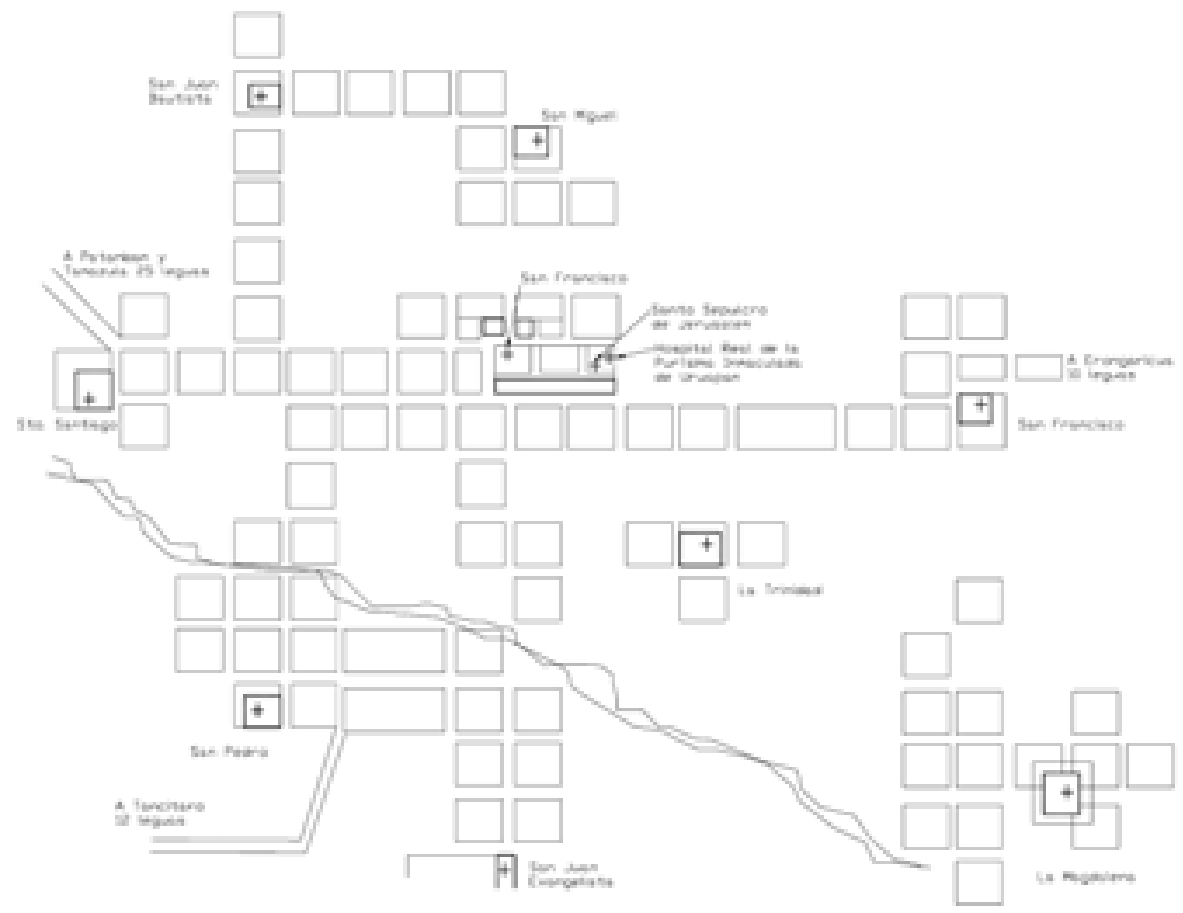

Figura 21. Uruapan. Planta de la población en el siglo XVI, según el trazado de Fray Juan de San Miguel. Basado en la reconstitución de Aldo Zurita en Juan B. Artigas, Pueblos, Hospitales y Guatáperas de Michoacán, p. 52.

34. Fray Isidro Félix de EsPINOSA, Crónica de la Provincia franciscana de los Apóstoles, San Pedro y San Pablo de Michoacán, en Federico Gómez de OrOzco, op. cit., p. 158.

35. José Bravo Ugarte, op. cit., p. 111. 


\section{Capilla del Santo Sepulcro, URUapan}

La capilla del Santo Sepulcro es la principal del hospital de Uruapan, "fundada bajo el Real Patronato y por ello llamada 'Hospital Real', bajo la advocación de la Purísima Concepción de Uruapan"36.

En la Inspección Ocular de Michoacán la mencionan como "bastante aseada, con un altar dorado y enfrente del edificio de altos del hospital, que indica haber sido en otro tiempo obra aplicada a los enfermos; pues aún existen las señales de las enfermerías, botica y otras oficinas, que hoy están sin uso, abandonadas y en un estado de ruina..." ${ }^{37}$. La portada de la capilla tiene un arco de medio punto enmarcado por un alfiz, sobre el cual hay una hornacina con una escultura de San Francisco de Asís. Al lado de ella hay dos escudos de piedra, uno de la orden de San Francisco y el otro "fue el escudo de los reyes de España y del cual únicamente se conserva la corona, pues al igual que sus similares, fue destruido en los primeros años de nuestra independencia" ${ }^{\prime \prime 8}$ (véase figura 22).

Angulo describe esta portada diciendo "que no cede en riqueza a la de Chimalhuacán y que corresponde asimismo a la primera etapa del Renacimiento. Cortés vio en ella reminiscencias indígenas. Las enjutas muestran las típicas rosas, aquí casi yuxtapuestas, y el cerco se viste de menuda y tupida ornamentación renacentista que hace pensar en las yeserías peninsulares. Los candelabros de las jambas no se resignan a olvidar el estilo 'moderno' y sus tallos se mueven con ritmo análogo al que veremos en el Sanctorum de Tacuba" ${ }^{39}$.

La capilla es pequeña, tiene una nave rasa, con presbiterio del mismo ancho que la nave, diferenciado por un arco triunfal con relieves. La cubierta es un alfarje de un solo orden de vigas apoyado sobre gruesos canes decorados tanto en la parte superior como en la inferior con el cordón franciscano.

La cubierta del presbiterio tiene mayor altura que la nave y conserva el mismo tipo de techumbre (véase figura 25). En las paredes del presbiterio conserva importantes restos de pintura mural.

Tiene el hospital de Uruapan unas ventanas labradas en los corredores de singular belleza (véase figura 23). Están formadas por un cerramiento apoyado sobre un par de canes moldurados, que en conjunto asemejan un arco. Enmarcando el conjunto está un alfiz. Artigas compara estas ventanas con los arcos de las madrazas de Marruecos (véase figura 24). “Las ventanas de Uruapan y de Zacán siguen idéntica estructura. No se cierran con arcos de cantería sino con za-

\footnotetext{
36. Juan Benito Artigas, Pueblos..., p. 54.

37. José Bravo Ugarte, op. cit., p. 110.

38. Eduardo De Heredia, Fray Juan de San Miguel, fundador de Uruapan, Uruapan, 1925, en J.B. ARTIGAS, op. cit., p. 57.

39. Diego Angulo IÑIGUEZ, op. cit., p. 331.
} 


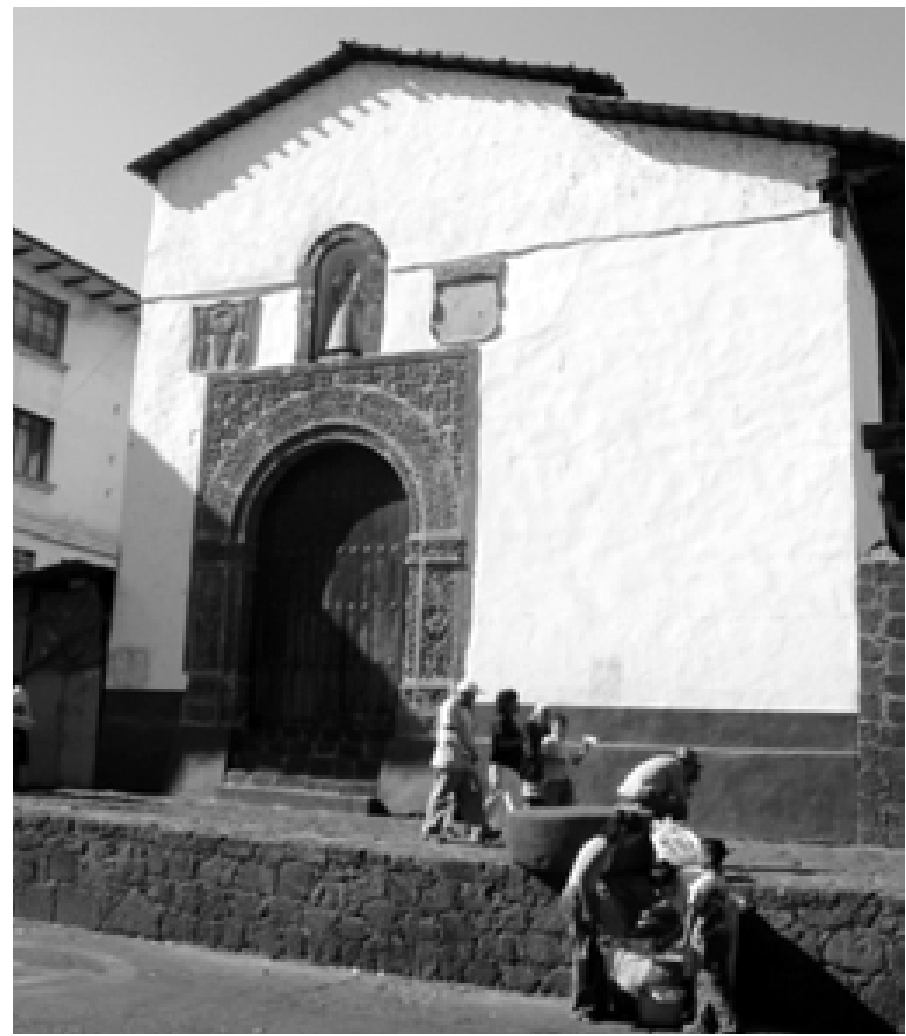

Figura 22. Capilla del Santo Sepulcro, Guatápera de Uruapan. Rodrigo Floresvillar Ortiz.

patas, las cuales, sucesivamente escalonadas conforme ganan elevación, disminuyen el claro, hasta que el dintel superior lo cierra totalmente. Los sistemas constructivos de la madera se reproducen aquí en piedra, lo mismo que había sucedido con los entablamentos de la arquitectura clásica de Grecia. El intradós del cerramiento así creado se recorta en sinuosas curvas y contracurvas creando formalmente, en la parte superior del hueco de la ventana, un arco polilobulado irregular de entrantes y salientes que pudieran parecer caprichosos. Prodigio formal. Tanto es así, que en un viaje por Marruecos en octubre de 1996, pude constatar la presencia de arcos semejantes e idéntico sistema constructivo, construidos allí en madera, en las universidades coránicas, madrazas o medersas, entre ellas la de Salé, en Rabat, la actual capital del reino"${ }^{40}$.

40. Juan Benito ARTigas, Pueblos..., p. 87. 


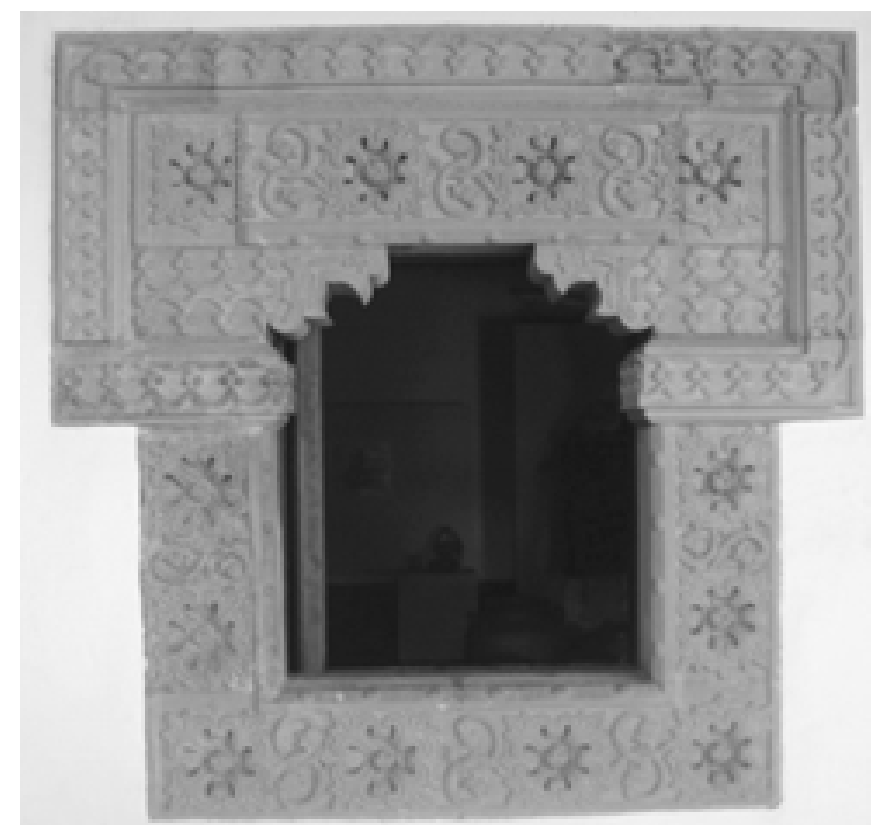

Figura 23. Guatápera de Uruapan, ventana. Inés Ortiz Bobadilla.

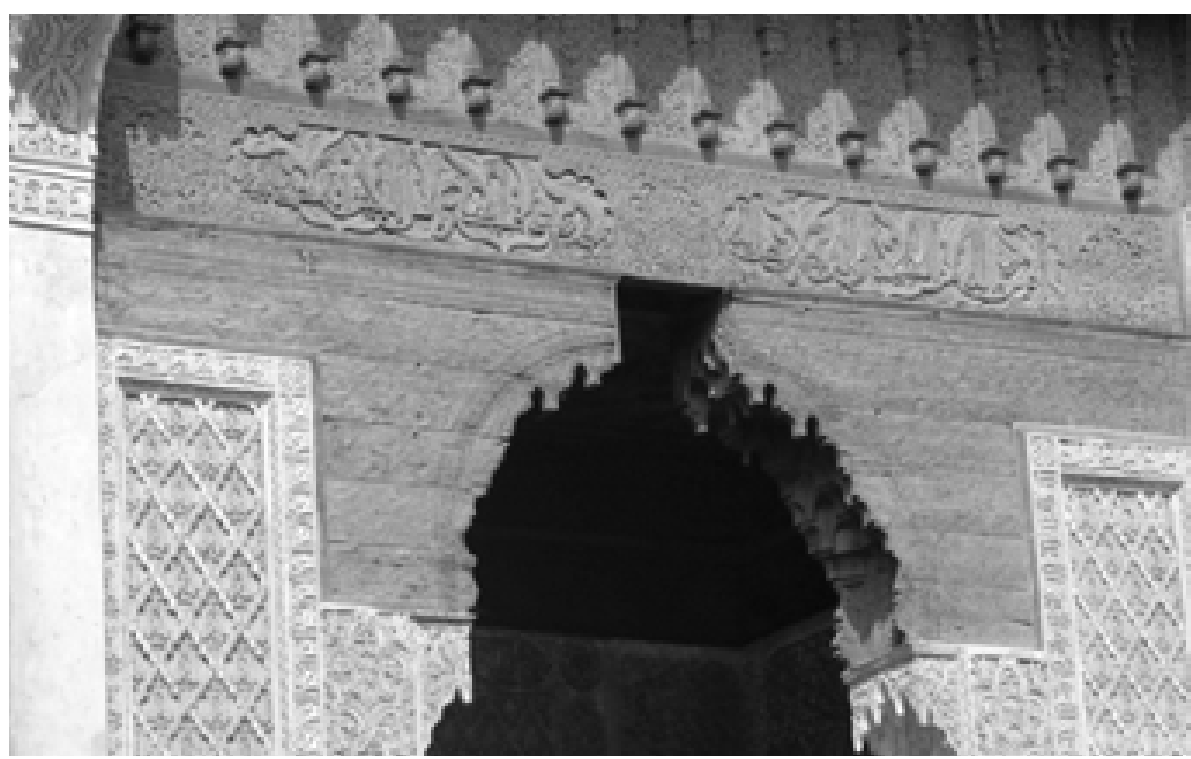

Figura 24. Detalle de uno de los accesos a la medersa, Marrakech, Marruecos. Inés Ortiz Bobadilla. 


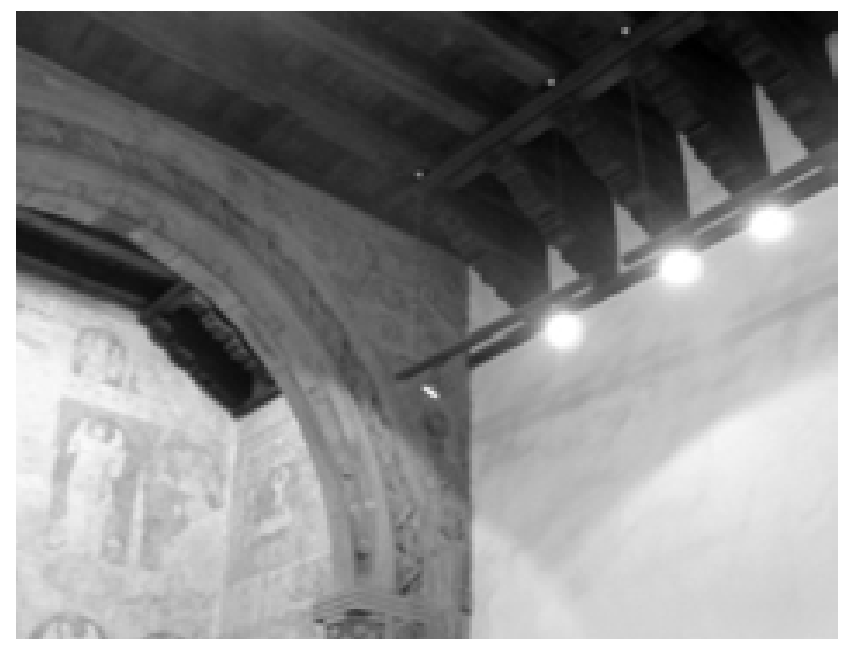

Figura 25. Vista del interior de la capilla del Santo Sepulcro, Uruapan. Rodrigo Floresvillar Ortiz.

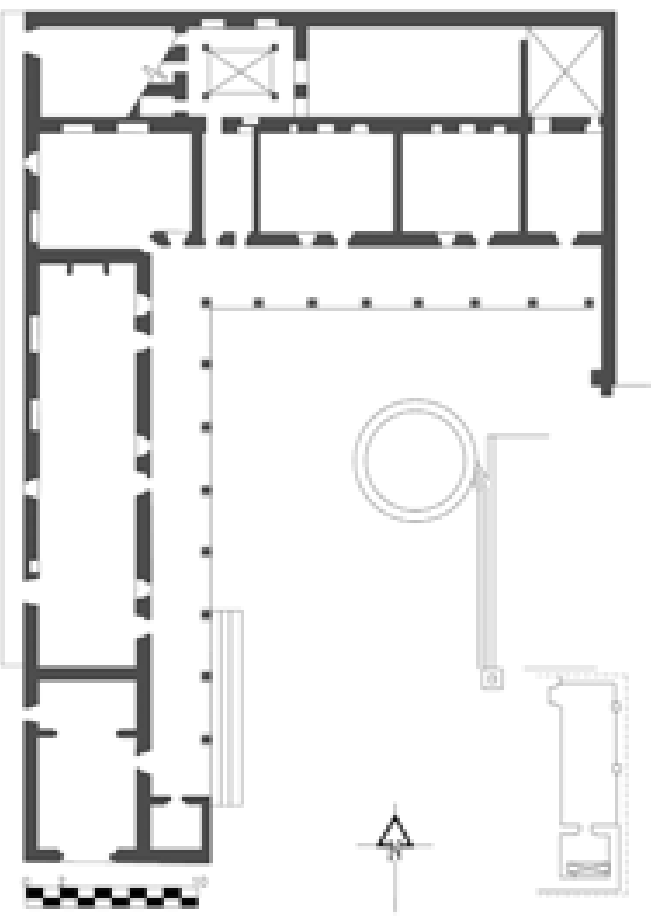

Figura 26. Planta general de la guatápera de Uruapan. Basado en Juan B. Artigas. 


\section{Capilla de SAN Francisco} Miguel.

Ésta es una de las nueve capillas de la traza original de Fray Juan de San

La portada de la capilla es muy sencilla, tiene un arco de medio punto y a los lados de éste, decoraciones con veneras (véase figura 27).

Se trata de una pequeña capilla de nave rasa, dividida en tres naves a modo basilical, separada cada nave por pies derechos de madera de sección cuadrada con bases de cantera. Sobre de ellos descansan las zapatas que soportan las vigas sobre las cuales se apoya la cubierta. La nave central tiene mayor altura que las laterales (véase figura 28). La cubierta central imita una armadura de par y nudillo, formando una cubierta trapezoidal con decoraciones de medallones; las naves laterales están cubiertas con alfarjes de un solo orden de vigas apoyadas sobre canes sencillos (véase figura 29). Al igual que la mayoría de las cubiertas de madera en Michoacán, se protege la cubierta interior con una armadura de madera, que es la que va a soportar las tejas.

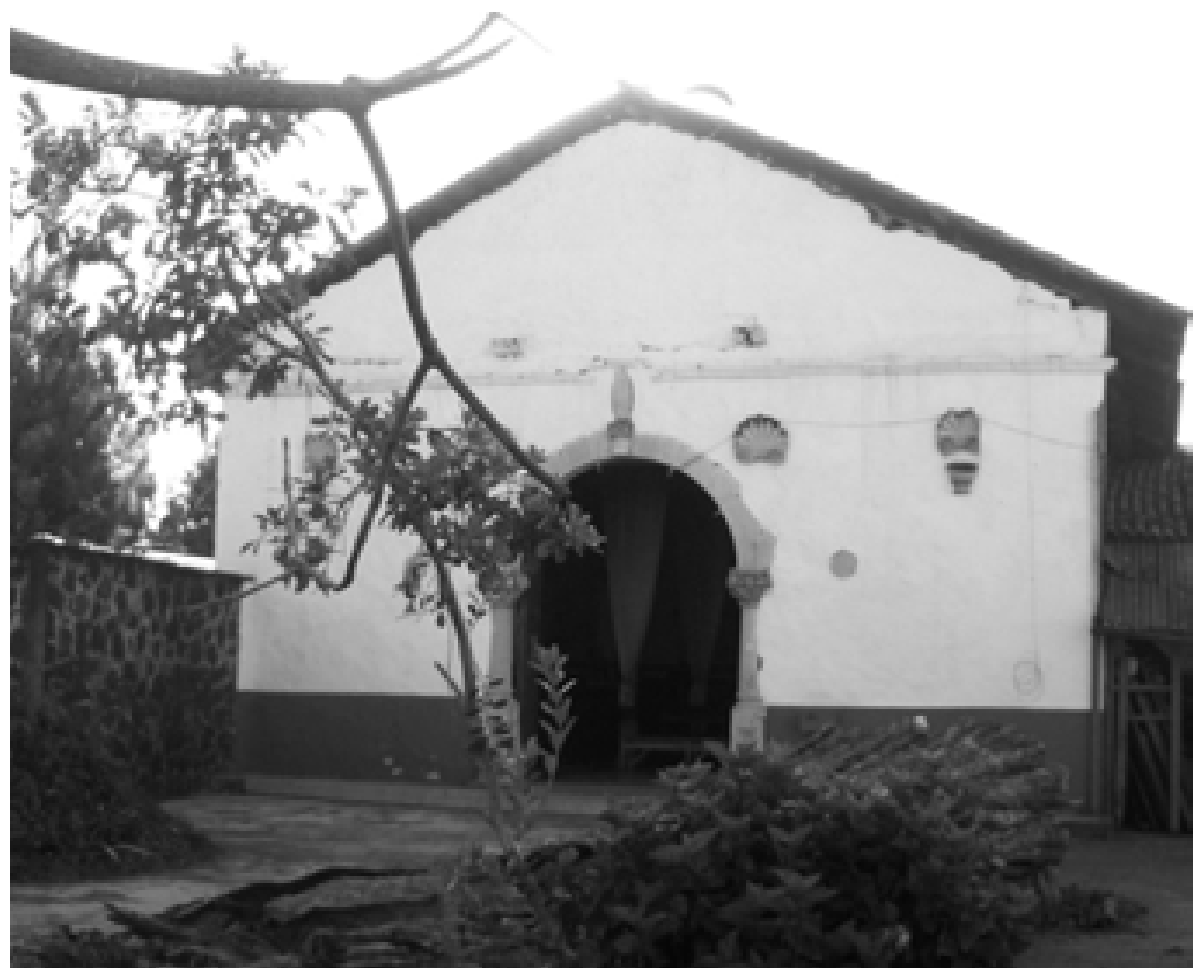

Figura 27. Fachada principal de San Francisco, Uruapan. Inés Ortiz Bobadilla. 

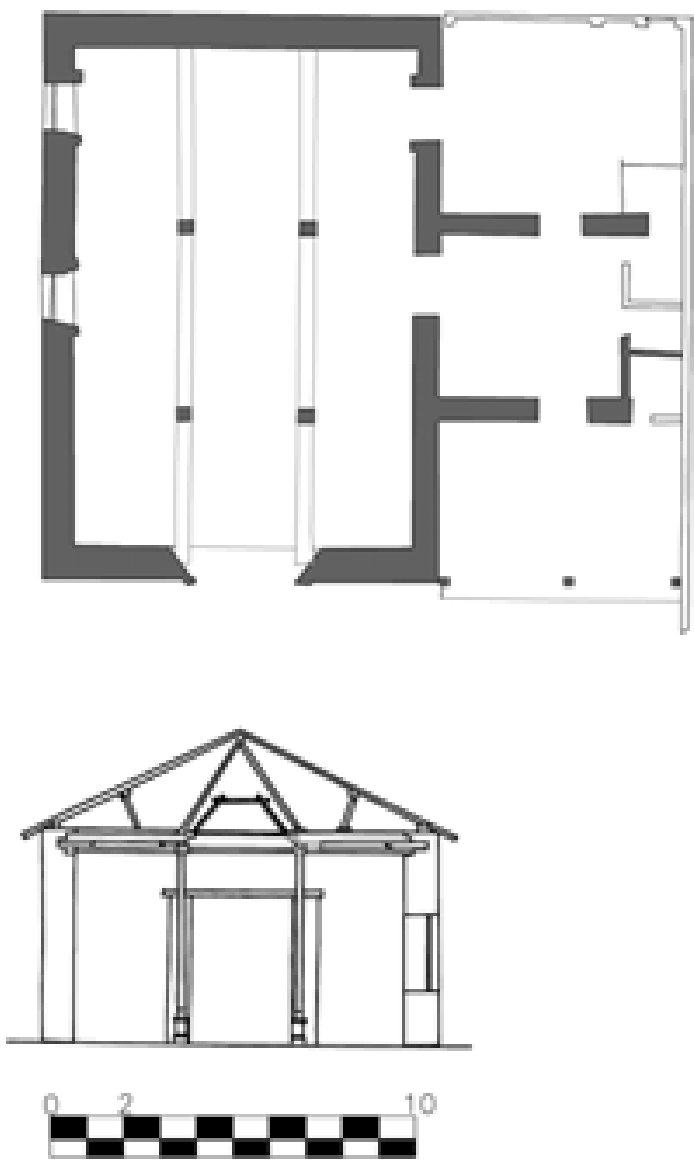

Figura 28. Planta y corte de San Francisco, Uruapan. Basado en G.A.R.

Toussaint menciona acerca de esta capilla "En Uruapan la capilla de San Francisco presenta una estructura mudéjar... Ésta presenta un techo que por el interior parece un remedo de los de par y nudillo, aunque esto no puede garantizarse pues está cubierto totalmente con tablas decoradas con pintura. El aspecto, sin embargo, es absolutamente oriental y se nota bien la influencia popular en la techumbre" ${ }^{\prime 4}$.

41. Manuel Toussaint, Arte mudéjar..., p. 37. 


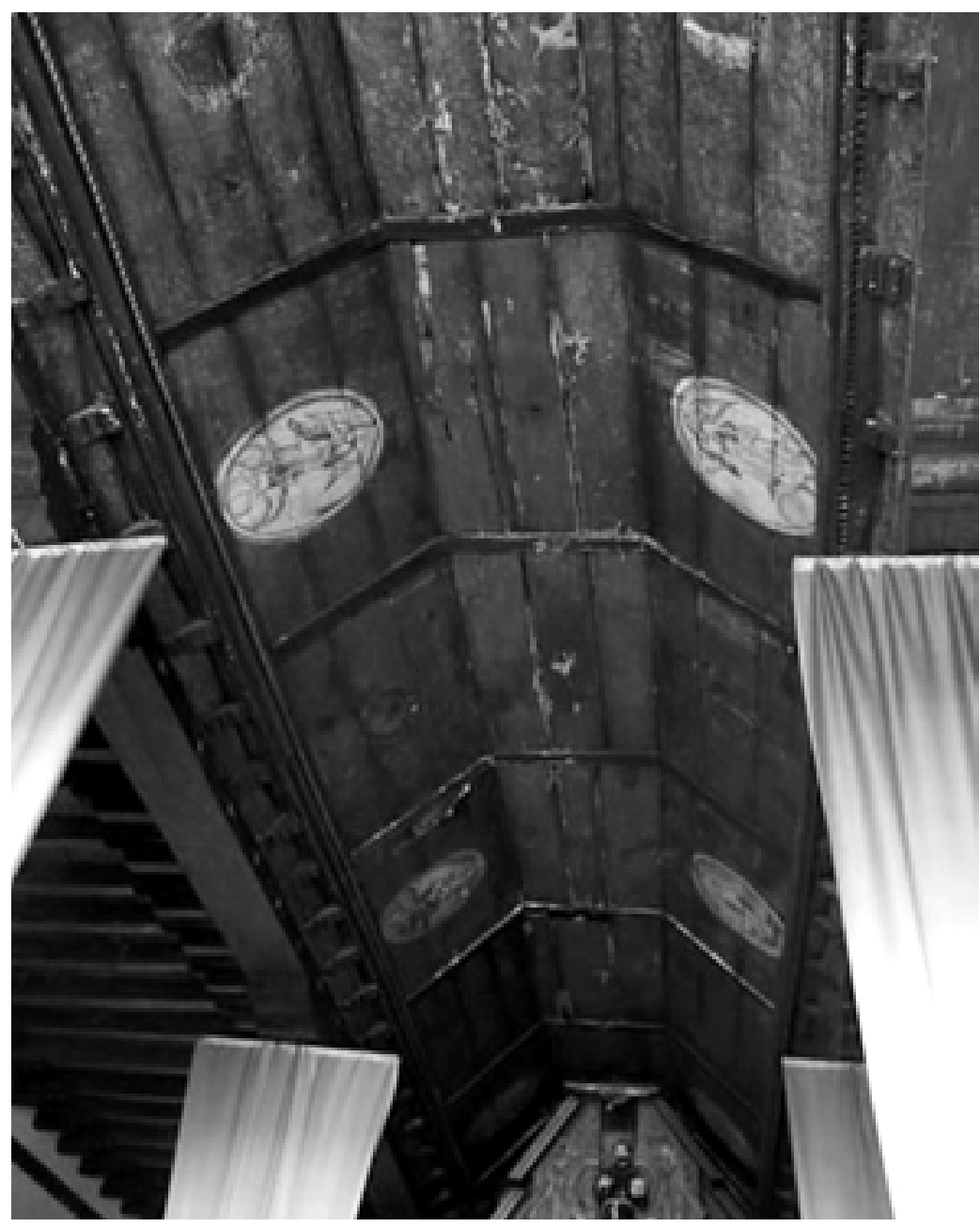

Figura 29. Interior de la capilla de San Francisco, Uruapan. Inés Ortiz Bobadilla.

\section{Capilla de San Miguel ArCángel}

Otra capilla de los barrios de Uruapan sería la de San Miguel Arcángel, su fachada está muy modificada, (véase figura 31) pero en su planta conserva el mismo esquema que la de San Francisco de Asís, nave rectangular con el ábside del mismo ancho que la nave y planta de tipo basilical, con la nave central más ancha que las laterales y dividida por medio de pies derechos (véase figura 30). 


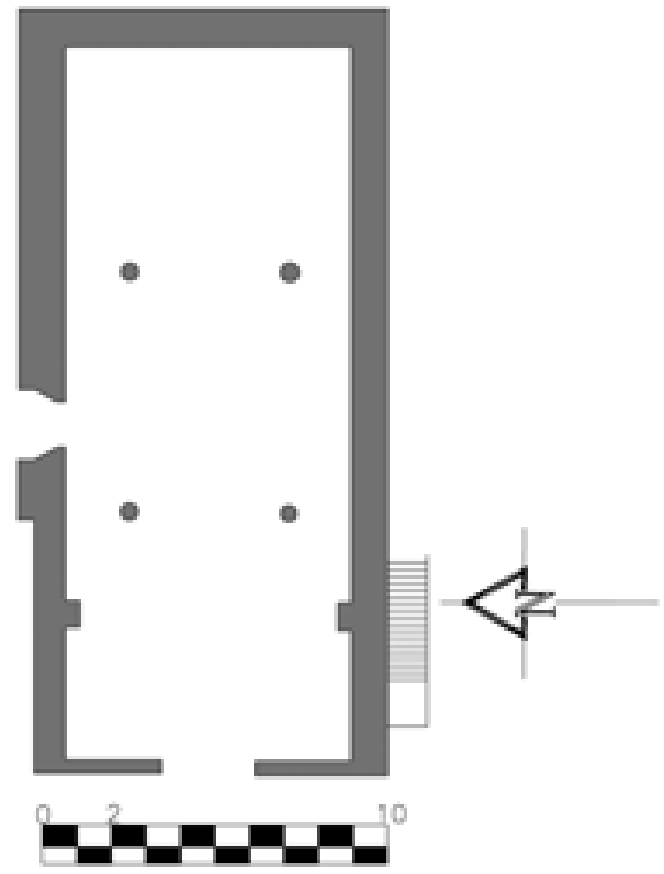

Figura 30. Plano de la capilla de San Miguel Arcángel, Uruapan. Basado en G.A.R.

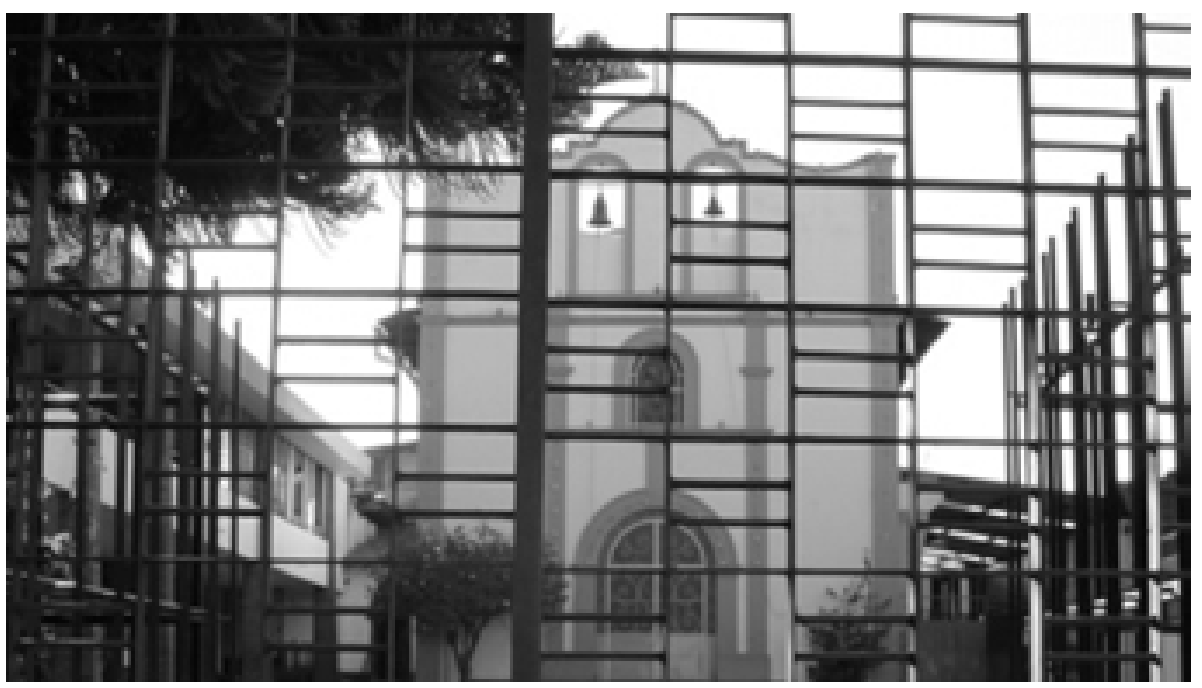

Figura 31. Fachada principal de la capilla de San Miguel Arcángel, Uruapan. Inés Ortiz Bobadilla. 


\section{Capilla del SeÑor Santiago Apóstol}

Esta capilla data del siglo XVI y está localizada en el barrio de Santiago Apóstol, en Uruapan, Michoacán.

Se trata de una de las nueve capillas que se construyeron en los nueve barrios de Uruapan.

La fachada está muy modificada; tiene un arco de medio punto encuadrado por un alfiz, sobre éste hay un relieve del apóstol Santiago (véase figura 32). La planta es pequeña de tres naves, a modo de planta basilical. Las naves están separadas por pies derechos de madera. La nave central es más ancha y alta que las laterales. La cubierta pudo haber sido en su origen una armadura de par y nudillo en la nave central y colgadizos en las naves laterales.

Actualmente la nave central tiene un cañón corrido y las naves laterales están cubiertas con un alfarje de un solo orden de vigas, apoyadas sobre canes.

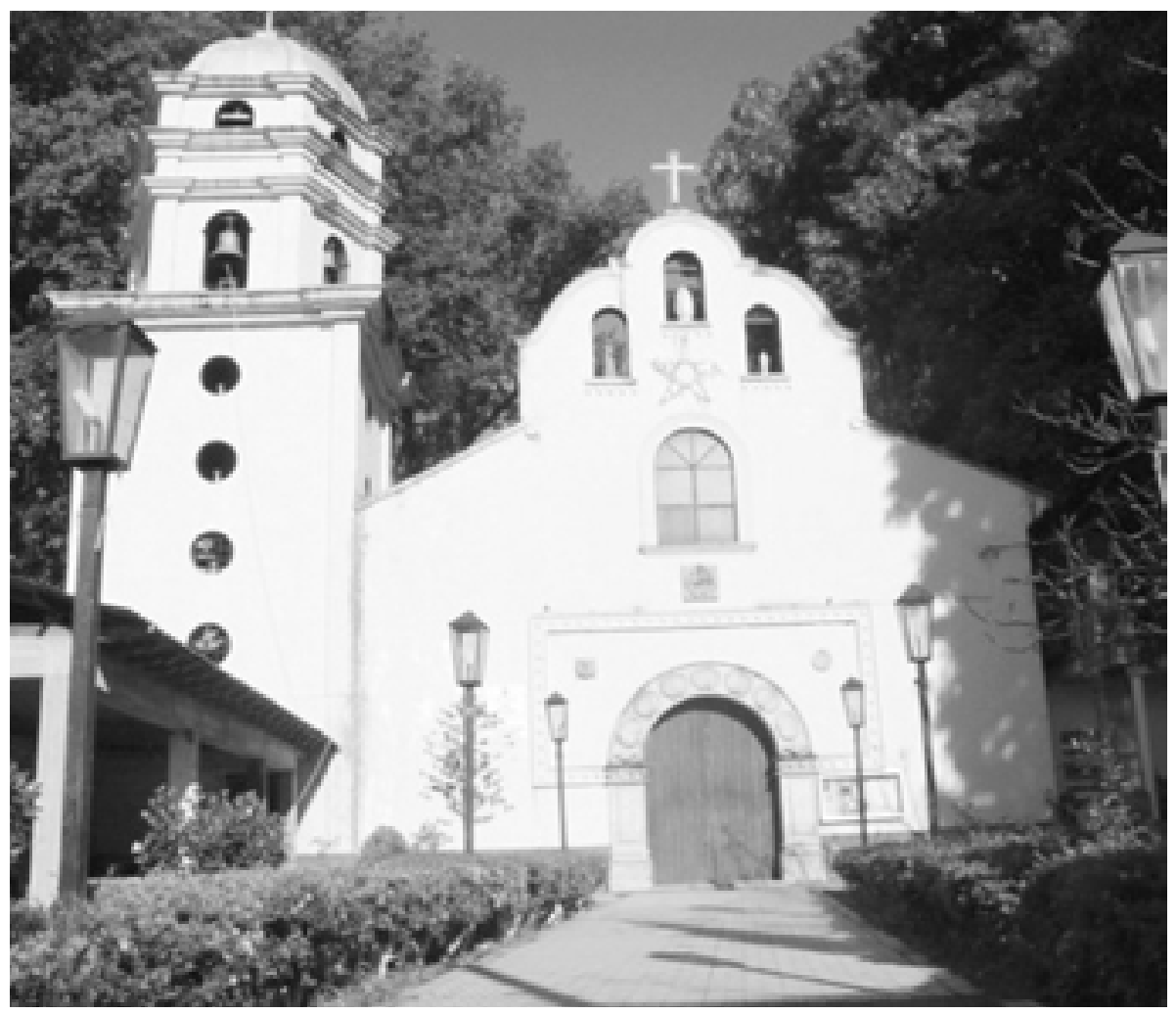

Figura 32. Fachada principal de la capilla de Santiago Apóstol, Uruapan. Rodrigo Floresvillar Ortiz. 


\section{Iglesia de SAN Pedro y Capilla del Hospital, ZaCÁN}

En este lugar se encuentra el antiguo convento de San Pedro, fundado en 1560 y reconstruido en 1691. En la portada del templo hay un relieve que indica la fecha de 1560. Probablemente fue fundado por los franciscanos para pasar posteriormente a manos de los agustinos.

En la Inspección Ocular en Michoacán, se describe el edificio como "una nave despejada, de piedra y lodo, cubierta de tejamanil, torre adjunta, debajo el baptisterio, piezas separadas de antesacristía y sacristía desalineadas, coro alto, buen entablado superior, malo el inferior y 11 altares con sus retablos, 8 nuevos, dos dorados, y todos de fea talla" ${ }^{\prime 2}$.

Se trata de una iglesia con una nave rasa, con presbiterio del mismo ancho que la nave, diferenciado tan solo por un desnivel en el piso. El coro, al inicio de la nave, está apoyado sobre vigas que apean en canes sencillos. La cubierta está realizada con un alfarje de un solo orden de vigas apeadas sobre canes sencillos, con molduras tanto inferior como superior, con forma de cordón franciscano (véanse figuras 34 y 35).

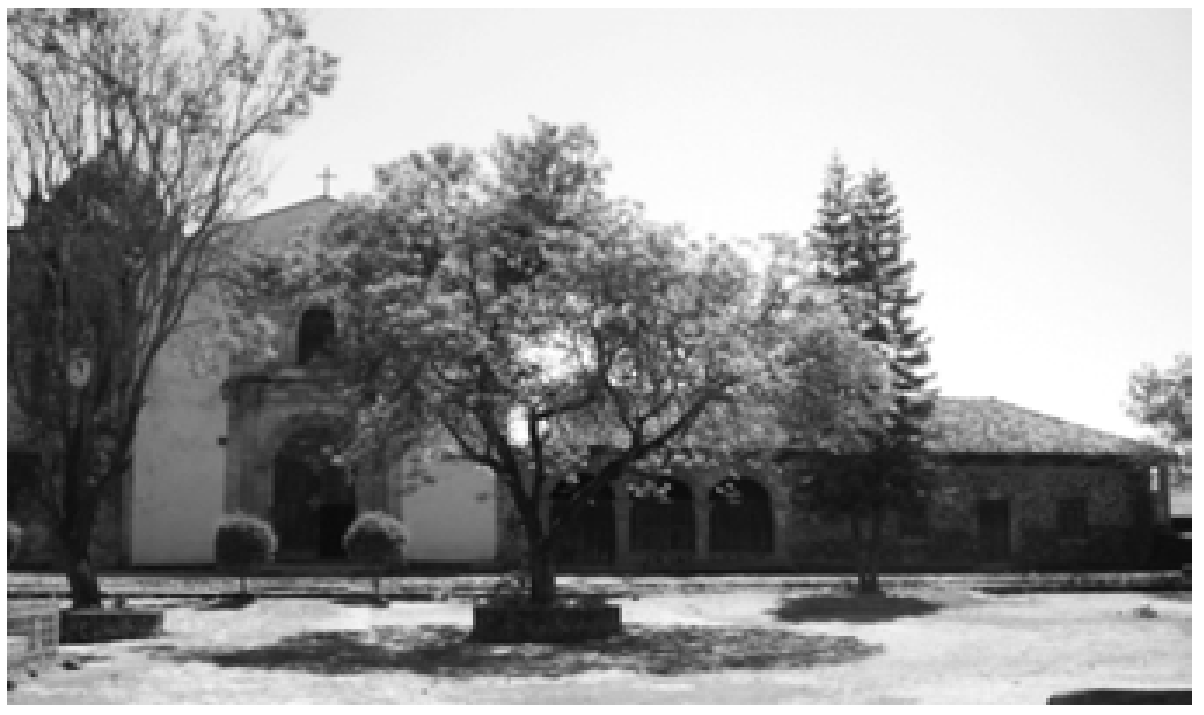

Figura 33. Fachada principal de la iglesia de Santa Ana, Zacán. Rodrigo Floresvillar Ortiz.

42. José Bravo UGarte, op. cit., p. 95. 


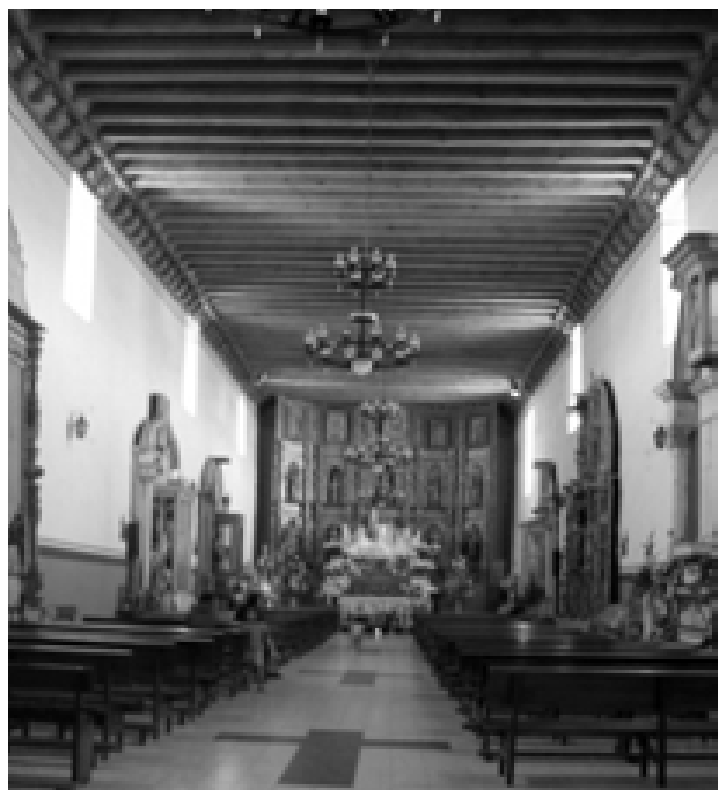

Figura 34. Vista del presbiterio, Santa Ana, Zacán. Rodrigo Floresvillar Ortiz.

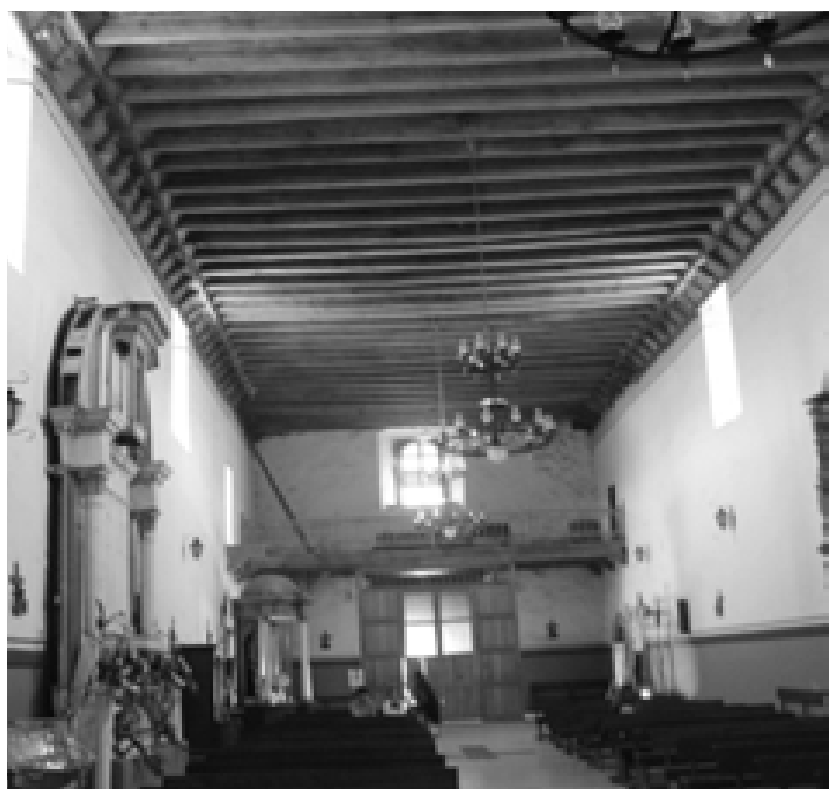

Figura 35. Vista del coro, Santa Ana, Zacán. Rodrigo Floresvillar Ortiz. 


\section{CAPIlla de la InMaculada o de SANTA Rosa}

En la Inspección Ocular nos dicen: “La capilla del Hospital es de piedra y lodo, techo nuevo de tejamanil, destruido el entablado inferior, empezado el superior, y un altar con su retablo dorado de mala escultura y notable desaseo. Existe todavía adjunto el antiguo Hospital destinado hoy a alojar al cura" ${ }^{\prime 3}$.

La portada de la capilla ha desaparecido, actualmente tiene el acceso únicamente delineado por un cerramiento y dos postes de madera, sobre éste una pequeña ventana perteneciente al coro, con material reutilizado de alguna de las ventanas del hospital.

La planta de la capilla es de una sola nave a modo de planta basilical, dividida en tres naves por medio de pies derechos de madera, sobre los cuales descansan zapatas, la nave central es más ancha que las laterales, el presbiterio es del mismo ancho que la nave, diferenciado tan solo por un escalón. Al inicio de la capilla se encuentra el coro, apoyado sobre vigas de madera, con una escalera del mismo material para acceder al entrepiso. La cubierta de la capilla es de un alfarje de un solo orden de vigas en las naves laterales y en la nave central imita un alfarje de par y nudillo, logrando un espacio trapezoidal. Hay dos tirantes colocados a la mitad de los vanos entre los pies derechos. Tiene decoración pictórica en toda la cubierta. En una viga del sotocoro está escrita la fecha de 1857.

Existen al interior del hospital, en los corredores del pasillo, unas ventanas muy parecidas a las ventanas del hospital de Uruapan. Labradas en piedra, formadas en este caso por dos cerramientos apoyados sobre un par de canes moldurados, del mismo material, que en conjunto asemejan un arco. La ventana está enmarcada por un alfiz (véase figura 38).

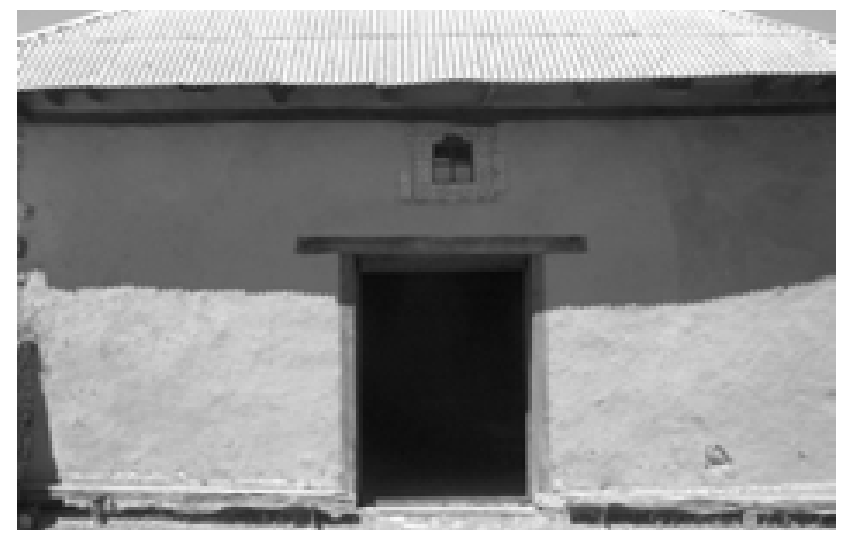

Figura 36. Fachada principal de la capilla de la guatápera, Zacán. Inés Ortiz Bobadilla.

43. Ibídem. 


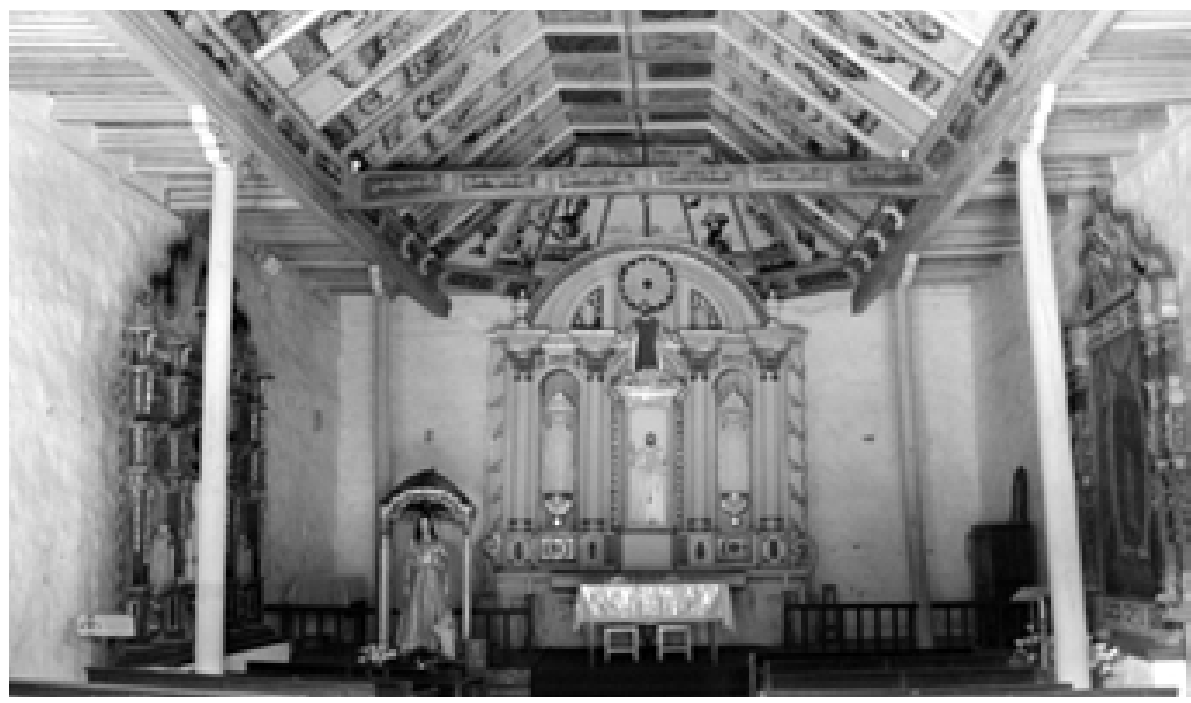

Figura 37. Vista del interior de la capilla de la guatápera, Zacán. Inés Ortiz Bobadilla.

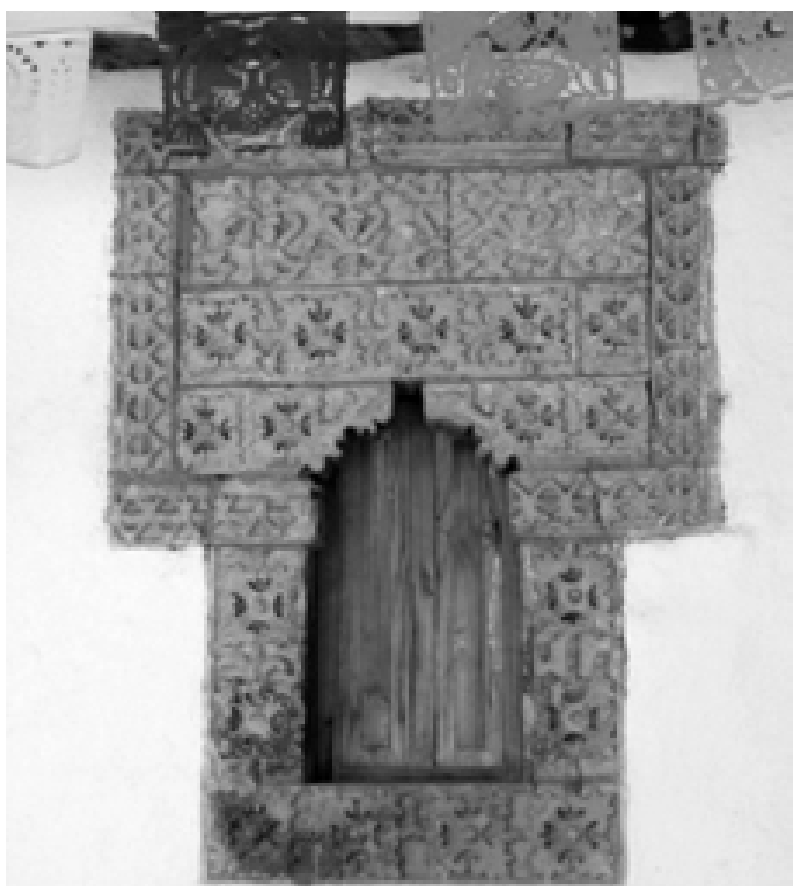

Figura 38. Detalle de las ventanas de los corredores de la guatápera, Zacán. Inés Ortiz Bobadilla. 


\section{Iglesia de SANTIAgo Apóstol y Capilla del Hospital, ANGAHUAN}

Angahuan significa en lengua tarasca "lugar donde se come" o "lugar de comida". Aquí fue fundado el conjunto, según Kubler, en 1570 "por canon del consejo capitular de la catedral de Michoacán" ${ }^{44}$ y según Toussaint en 1577, por una inscripción en el interior del edificio ${ }^{45}$, por Fray Jacobo Daciano, originario de Dacia, actual Rumania.

Angahuan fue iglesia de visita, dependía del curato de Zirosto y después pasó a manos de los agustinos. Según la Inspección Ocular en Michoacán la iglesia tenía "un cañón angosto de piedra y mezcla, torre adjunta y mirador de lo mismo, techo de tejamanil, sacristía desaseada, coro alto con órgano desbaratado, entablados inferior y superior, pero éste de una construcción muy prolixa; pues la madera que le compone está en talla de filigrana de mal gusto, cinco altares formales con sus retablos dorados de fea escultura, viejos, manchados y poco decentes" ${ }^{\prime \prime 6}$.

La portada de Angahuan tiene un vano de medio punto enmarcado por un alfiz, sobre éste otro alfiz que sirve de base para la ventana del coro, la cual está compuesta, a la manera de Uruapan y Zacán, con dos cerramientos apoyados sobre dos canes moldurados, que van a formar el arco del vano, todo enmarcado por un tercer alfiz. Toussaint habla de esta portada, "en ella se mezclan el sabor renacentista, plateresco del conjunto, los resabios mudéjares en los alfices que se sobreponen en forma verdaderamente extraña, y el gusto indígena puro en la técnica de sus menudos relieves" ${ }^{\prime \prime 7}$.

La iglesia es de una nave rasa, con presbiterio ligeramente menor al ancho de la nave, diferenciado por un arco triunfal y por un desnivel en el piso; el espesor de los muros es de 1 vara $(0,8359 \mathrm{~m})^{48}$. Probablemente tuvo una cubierta de alfarje, tanto en la nave como en el presbiterio, como apunta Toussaint, "ha desaparecido el alfarje que cubría la nave; el presbiterio, que es más angosto, debe haber poseído otro alfarje, en la actualidad ostenta un techo en forma de batea formado por triples canes y baquetones entre ellos, tablas que cubren los espacios y otras que forman harneruelo. A todo lo largo de las paredes se ve

44. George Kubler, op. cit., p. 232.

45. Manuel Toussaint, Arte mudéjar..., p. 26.

46. José Bravo UGARTE, op. cit., p. 90.

47. Manuel Toussaint, Arte colonial..., p. 26.

48. Juan CABrera AceVes, Aspectos conceptuales en la fundación de los templos franciscanos edificados en la zona histórica purépecha, en Eugenia María Azevedo SAlomao (coord.), Michoacán Arquitectura y Urbanismo, Morelia, Michoacán, México, UMSNH, Facultad de Arquitectura, División de Estudios de Posgrado, 1999, p. 247. 


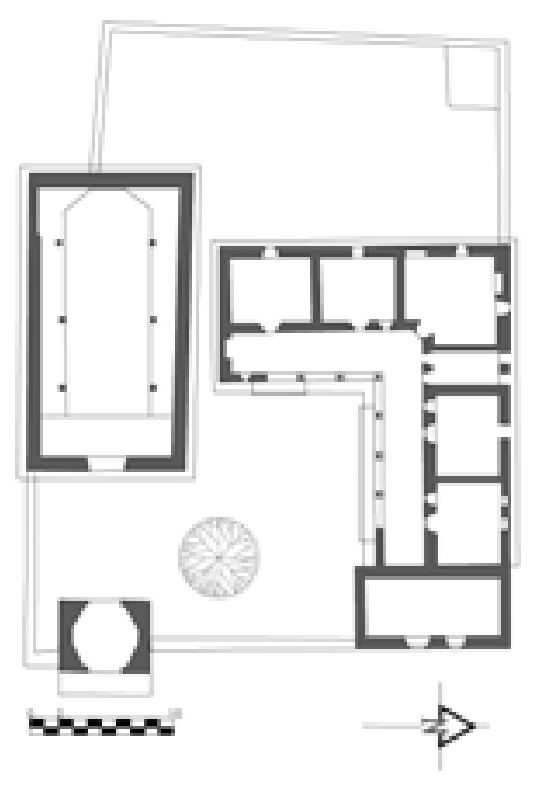

Figura 39. Plano del Hospital, Zacán. Basado en Juan B. Artigas.

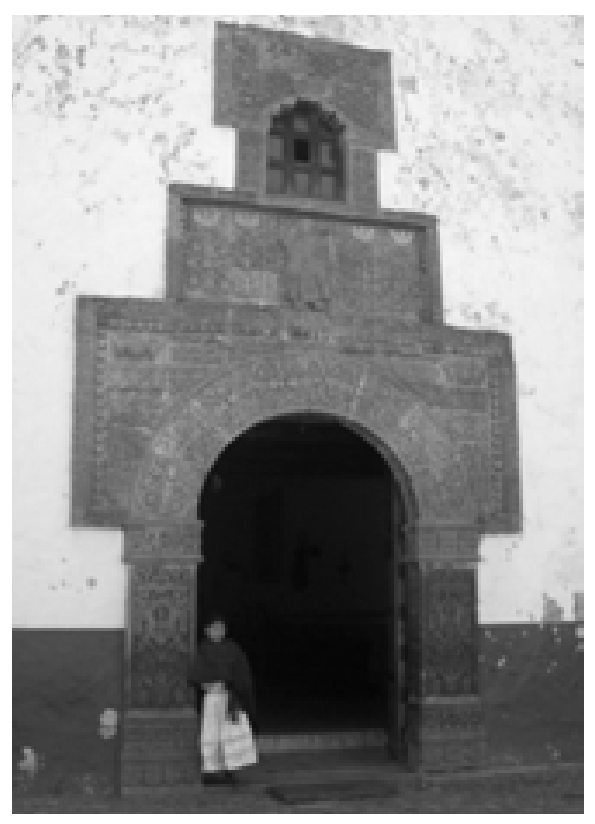

Figura 40. Fachada principal del templo de Santiago Apóstol, Angahuan, Michoacán. Leonardo Floresvillar Ortiz.

un arrocabe o friso con inscripción que semeja escritura cúfica y al final, una fecha que puede corresponder al edificio: 1577"49.

Según Gloria A. Álvarez, la cubierta de la iglesia estaba hecha con un cañón corrido que fue sustituida a mediados del siglo XVIII por una bóveda de cañón escarzano. Sin embargo el presbiterio no se modificó, éste tiene la forma de una gran artesa invertida, apoyada sobre triples canes, divididos con molduras en forma de cordones, con tablillas decoradas entre cada can. En lo que vendría a ser el almizate está decorado con cuatro estrellas de doce puntas y angelitos en cada esquina. El coro, al inicio de la nave, está apoyado sobre un alfarje de un solo orden de vigas que apea sobre canes sencillos.

La capilla del hospital, construida probablemente en 1570 por una inscripción en la fachada, también es referida por la Inspección Ocular de Michoacán, "La capilla del Hospital es también de piedra y mezcla con piso entablado, coro alto y artesón, feos, antiguos y poco seguros, y un solo altar con su retablo dorado semejante a los de la iglesia" ${ }^{20}$. Tiene una portada sobria,

49. Manuel Toussaint, Arte mudéjar..., p. 28.

50. José Bravo UGARTE, op. cit., p. 90. 


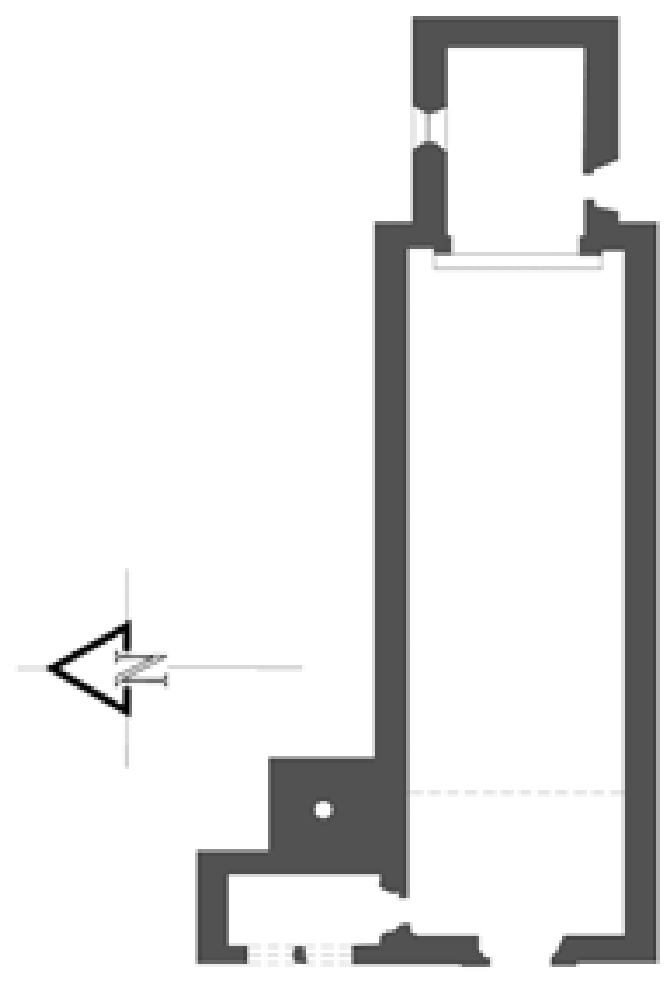

Figura 41. Planta del templo de Santiago Apóstol, Angahuan, Michoacán. Basado en Gloria A. Álvarez.

con un arco de medio punto, enmarcado por un alfiz. En la parte superior al acceso, una pequeña ventana de medio punto. Se trata de una nave rasa de pequeñas dimensiones, con presbiterio del mismo ancho que la nave, diferenciado por un escalón. La cubierta está realizada por un alfarje de un solo orden de vigas apoyado sobre canes, de reciente manufactura. Ya no posee coro. Cubre el alfarje una armadura de madera a dos aguas.

Se hizo una restauración en el inmueble "inyectando morteros expansivos en las fisuras y restituyendo las piezas de sillería faltantes. El alfiz de la portada se junteó utilizando resinas epóxicas, la bóveda de mampostería se consolidó después de corregir las pendientes y, finalmente, se procedió a recuperar los niveles del atrio" ${ }^{\prime \prime 2}$.

51. SAHOP, Secretaria de Asentamientos Humanos y Obras Públicas, México, Ed. Miguel Galas S.A., 1982, p. 82. 


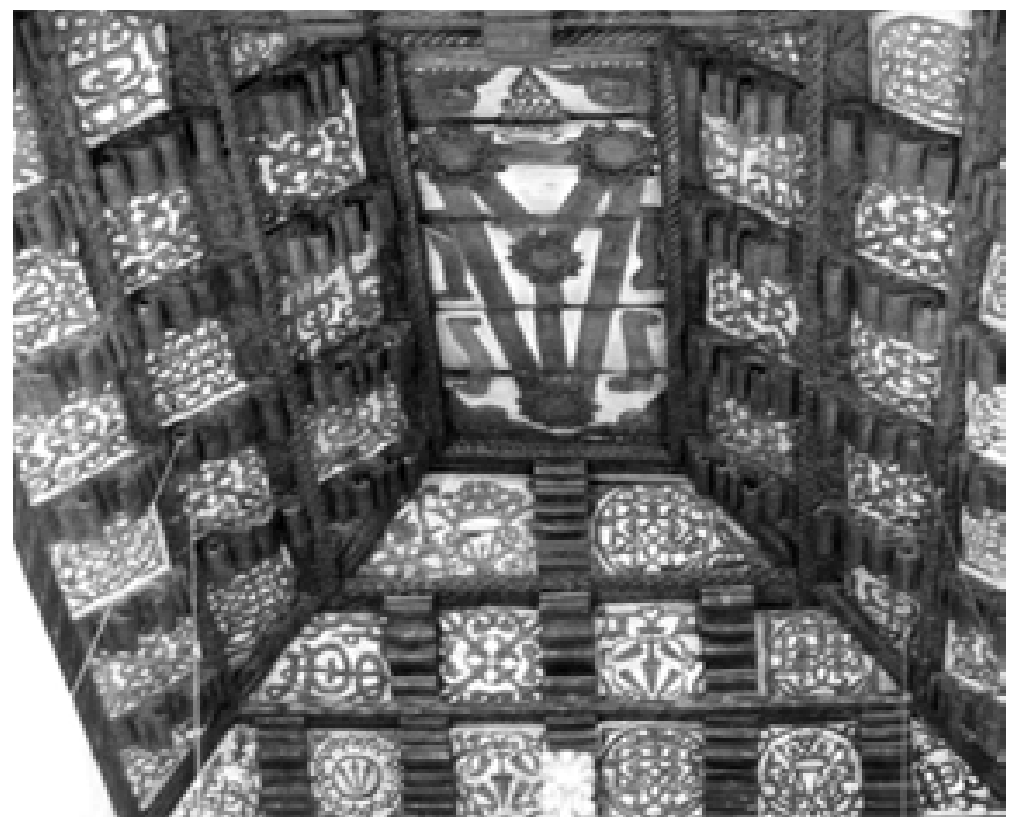

Figura 42. Cubierta del presbiterio, templo de Santiago Apóstol, Angahuan, Michoacán. Leonardo Floresvillar Ortiz.

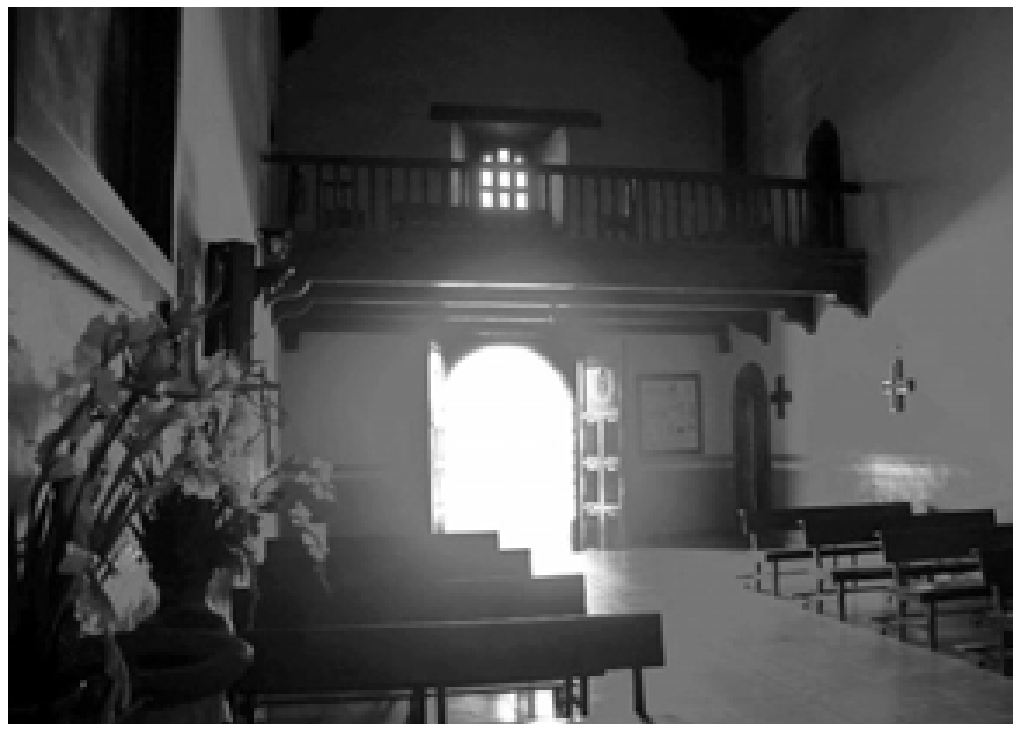

Figura 43. Interior del templo de Santiago Apóstol, Angahuan, Michoacán. Leonardo Floresvillar Ortiz. 


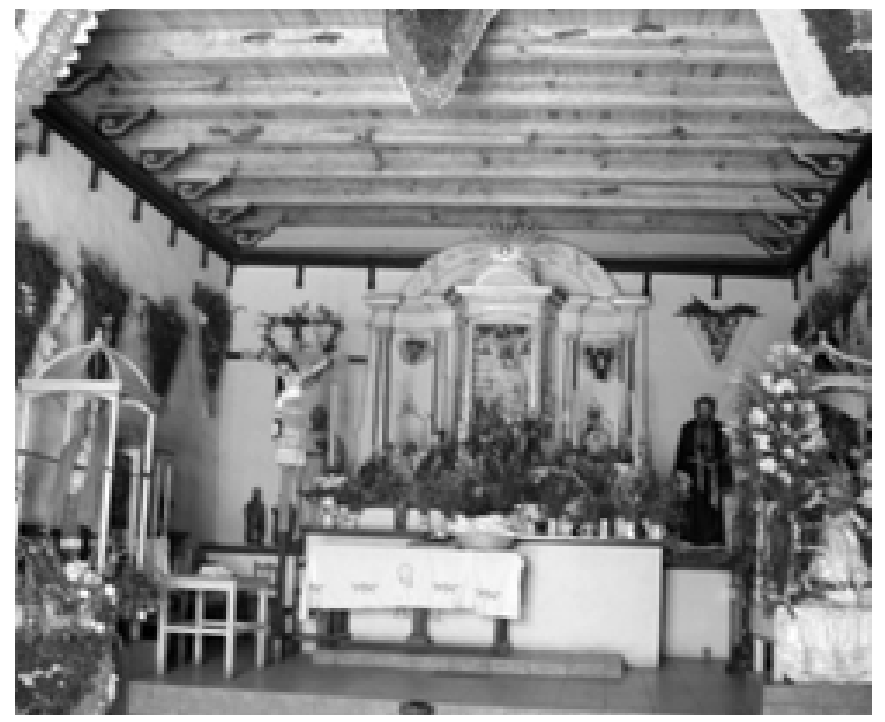

Figura 44. Interior de la capilla del hospital, Angahuan. Leonardo Floresvillar Ortiz.

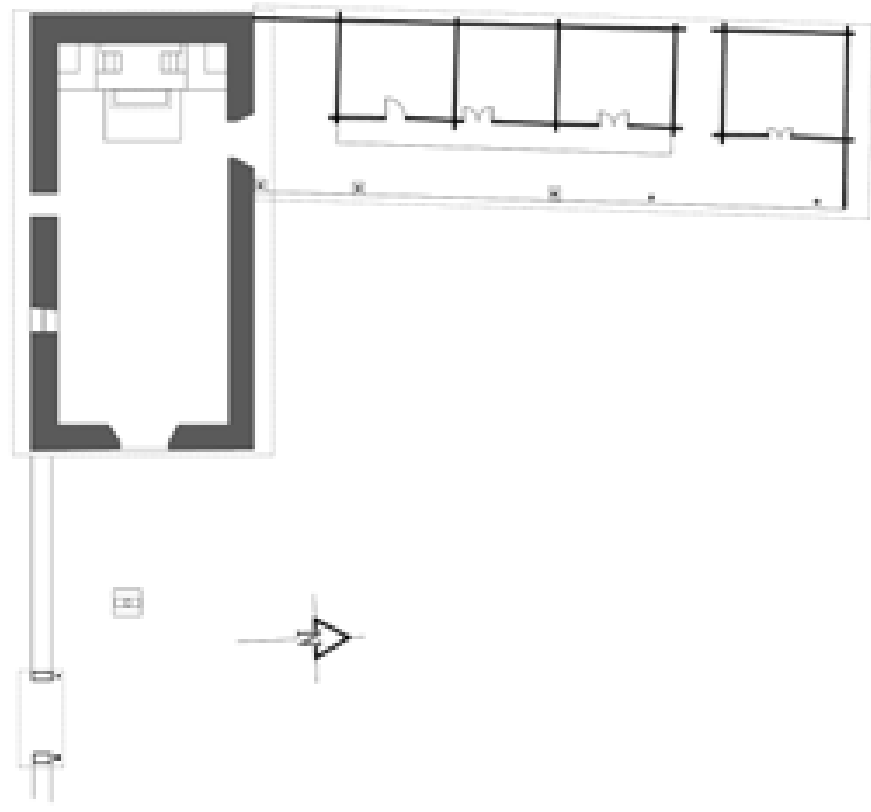

Figura 45. Planta de la capilla del hospital, Angahuan. Basado en Juan B. Artigas. 


\section{CONCLUSIONES}

Durante el virreinato hubo una acelerada construcción en la Nueva España, principalmente en lo referente a los edificios religiosos. Había un interés por convertir a la población a la religión que tenían los conquistadores.

La arquitectura que se efectuó durante este tiempo tiene elementos que reflejan su vínculo con el arte mudéjar. Hubo una gran proliferación de estructuras de madera, sobre todo en las cubiertas, ya que era el sistema estructural que conocían los españoles y de algún modo era un sistema más sencillo y más rápido que la elaboración de bóvedas. En la región de Michoacán existieron, según las fuentes históricas, verdaderas cubiertas mudéjares, como fue el caso de Tiripetío. Desafortunadamente un gran número de cubiertas de madera se perdieron a causa de incendio, falta de mantenimiento y abandono. En esta región, por tratarse de una zona maderera, las cubiertas siguieron sustituyéndose por otras de madera, pero ya sin seguir las técnicas estructurales mudéjares, sino incorporando las técnicas indígenas propias de la zona, creando cubiertas trapezoidales, que a la vista parecen armaduras de par y nudillo.

\section{RESUMEN}

El presente trabajo forma parte de una investigación acerca de la arquitectura mudéjar en la Nueva España en la que se analizan los elementos estructurales y arquitectónicos que influyeron en esta arquitectura. En este caso se hablará del estado de Michoacán. La incorporación de los sistemas estructurales, principalmente las cubiertas de madera, tienen semejanzas significativas que los relacionan con la arquitectura mudéjar de la Península Ibérica. Sin embargo, en el estado de Michoacán surgen cubiertas con ciertas particularidades que, si bien siguen la misma tectónica de las armaduras de par y nudillo, estructuralmente tienen soluciones diferentes.

Palabras clave: mudéjar, carpintería de lo blanco, virreinato, Michoacán, Nueva España.

\section{ABSTRACT}

The present work forms part of a research about the mudejar architecture in New Spain in which the structural and architectonical elements that influenced this architecture are analyzed. In this case it will be spoken about the state of Michoacán. The incorporation of the structural systems, mainly the wood covers, have significant similarities that relate them to the mudejar architecture of the Iberian Peninsula. Nevertheless, in the state of Michoacán, they arise covers with certain particularities that follow the same tectonic that the armors of "par y nudillo", but structurally they have different solutions. Spain.

Key words: Mudejar, carpentry of white, viceroyalty, Michoacán, New 